NBER WORKING PAPER SERIES

\title{
TAIL AND CENTER ROUNDING OF PROBABILISTIC EXPECTATIONS IN THE HEALTH AND RETIREMENT STUDY
}

\author{
Pamela Giustinelli \\ Charles F. Manski \\ Francesca Molinari \\ Working Paper 24559 \\ http://www.nber.org/papers/w24559 \\ NATIONAL BUREAU OF ECONOMIC RESEARCH \\ 1050 Massachusetts Avenue \\ Cambridge, MA 02138 \\ April 2018
}

We thank Maura Coughlin, Adam Karabatakis, and Miriam Larson-Koester for able research assistance. We received useful feedback from seminar participants at the HRS work-in-progress series, Bocconi University, University of Southampton, NYU CUSP, University of Michigan, Purdue University, Laval University, University of Oslo, Statistics Norway, University of Munich, and University of Padova, as well as from participants in the 2016 NYFed and ESRC RCMiSoC Workshop on Subjective Expectations. Giustinelli gratefully acknowledges support from the National Institute on Aging (NIA P01-AG10179 and P30-AG012846), the National Science Foundation (SES1131500) for the University of Michigan node of the NSF-Census Research Network (NCRN), and the Michigan Institute for Teaching and Research in Economics (MITRE)'s Undergraduate Student Support program. Manski's research was supported in part by National Science Foundation grant SES-1129475. The views expressed herein are those of the authors and do not necessarily reflect the views of the National Bureau of Economic Research.

NBER working papers are circulated for discussion and comment purposes. They have not been peer-reviewed or been subject to the review by the NBER Board of Directors that accompanies official NBER publications.

(C) 2018 by Pamela Giustinelli, Charles F. Manski, and Francesca Molinari. All rights reserved. Short sections of text, not to exceed two paragraphs, may be quoted without explicit permission provided that full credit, including $(\odot$ notice, is given to the source. 
Tail and Center Rounding of Probabilistic Expectations in the Health and Retirement Study Pamela Giustinelli, Charles F. Manski, and Francesca Molinari

NBER Working Paper No. 24559

April 2018

JEL No. C81,D1,D84,I12,J14

\begin{abstract}
$\underline{\text { ABSTRACT }}$
A growing number of surveys elicit respondents' expectations for future events on a 0-100 scale of percent chance. These data reveal substantial heaping at multiples of 10 and 5 percent, suggesting that respondents round their reports. This paper studies the nature of rounding by analyzing response patterns across expectations questions and waves of the Health and Retirement Study. We discover a tendency by about half of the respondents to provide more refined responses in the tails of the scale than the center. Only about five percent provide more refined responses in the center than the tails. We find that rounding varies across question domains, which range from personal health to personal finances to macroeconomic events. We develop a two-stage framework to characterize person-specific rounding. The first stage uses observed responses to infer respondents' rounding practice in each question domain and scale segment. The second stage replaces each original point response with an interval, representing the range of possible values of the respondent's true latent belief implied by the degree of rounding inferred in the first stage. We study how the inferred rounding types in the first stage vary with respondent characteristics, including age and cognitive abilities.
\end{abstract}

Pamela Giustinelli

Department of Economics

Bocconi University

Milan, Italy

pamela.giustinelli@gmail.com

Charles F. Manski

Department of Economics

Northwestern University

2211 Campus Drive

Evanston, IL 60208-2600

and NBER

cfmanski@northwestern.edu
Francesca Molinari

Department of Economics

Cornell University

Ithaca, NY

fm72@cornell.edu 


\section{Introduction}

Judgements about the likelihood of future events are an important input for predictions and decisions by citizens, policy makers, and researchers. From the early 1990s on, surveys designed by economists have increasingly measured respondents' subjective expectations for future events using a 0-100 scale of percent chance. This endeavor was prompted by earlier empirical evidence and theoretical arguments demonstrating the greater informativeness of elicited probabilities for binary events relative to "yes/no" intention measures (Juster, 1966; Manski, 1990). Manski (2004, 2017), Attanasio (2009), Hurd (2009), van der Klaauw (2012), Armantier et al. (2013), Delavande (2014), Schotter and Trevino (2014), and Giustinelli and Manski (2018) review the literature from various perspectives.

The Health and Retirement Study (HRS), whose data we analyze in this paper, has measured probabilistic expectations biannually since its start in 1992; Juster and Suzmann (1995) describe the initial design. Section P of the HRS core questionnaire has been devoted to expectations measurement, each wave including about 25 to 35 questions spanning different domains of personal and macroeconomic uncertainty. From 2002 on, expectations have been consistently elicited on a 0-100 percent-chance scale, with many questions repeated across waves.

Questions eliciting expectations on a 0-100 percent-chance scale in principle enable respondents to report beliefs to the nearest 1 percent, encouraging a common rounding convention with minimal data coarsening. But how do respondents use the scale in practice? The accumulated evidence reveals that respondents tend to round their responses. Responses that are not a multiple of 5 or 10 percent occur infrequently. When observed, they tend to occur near the endpoints of the scale to convey very small or large probabilities.

Some authors have devoted special attention to responses of 0, 50, and 100 percent. Fischhoff and Bruine de Bruin (1999) and Bruine de Bruin et al. (2002) hypothesize that some respondents use 50 percent to signal epistemic uncertainty. Lillard and Willis (2001) and Hudomiet and Willis (2013) conjecture that respondents form full subjective distributions for the probability of an event and then 
report whichever of the values $(0,50,100)$ is closest to the mode of their distribution. We analyze reports of $(0,50,100)$ percent jointly with responses to the entire set of expectations questions asked. Systemic rounding of responses was observed as early as Dominitz and Manski (1997), who wrote (p. 272): "Most respondents do not round their responses to the values $(0,50,100)$, but rather to the nearest multiple of five.”

Rounding of expectations poses a series of challenges for statistical inference. First, rounding generates greater data coarsening than intended by the measurement scale. Second, the extent of rounding is not directly observable and may vary across respondents and/or questions. Third, the reasons why respondents round are incompletely understood.

Observed response patterns carry information about respondents’ rounding practices, but they do not reveal why respondents round. Manski and Molinari (2010) hypothesize that respondents may round to simplify communication and/or to convey partial knowledge. If respondents round to simplify communication, rounding generates a form of measurement error. However, the structure of the errors produced by rounding is different from that occurring in the classical errors-in-variables model.

Manski and Molinari studied respondent-specific response patterns across all expectations questions asked in the 2006 HRS. They found strong evidence of rounding, with the extent differing across respondents. They proposed use of a person’s response pattern across questions to infer the person’s rounding practice, the result being interpretation of reported numerical values as interval data.

In this paper, we significantly expand study of respondent-specific rounding patterns by analyzing responses across all expectations questions asked in the core HRS questionnaire between 2002 and 2014. This enables us to learn important new features of rounding practices.

Section 2 presents the main findings of our data analysis, with Supplementary Appendices reporting further details. We initially study each wave of the HRS separately and find that the respondent-specific rounding patterns reported by Manski and Molinari (2010) are stable across waves. We then pool data 
across waves. This yields rich respondent-specific data that enables us to probe more deeply than the earlier study.

We discover a tendency by about half of the respondents to provide more refined responses in the tails of the 0-100 scale than the center. In contrast, only about five percent of the respondents give more refined responses in the center than the tails. We find that respondents tend to report the values 25 and 75 more frequently than other values ending in 5 . We also find that rounding practices vary somewhat across question domains, which range in the HRS from personal health to personal finances to macroeconomic events.

Based on our examination of rounding practices in Section 2, Section 3 develops a framework that interprets each numerical response given by a respondent as an interval. We propose a two-stage algorithm. The first stage classifies each respondent into one of a set of mutually exclusive and exhaustive rounding types and places an upper bound on the amount of rounding each respondent is inferred to apply when reporting their expectations. The second stage assigns an interval to each of the respondent's original point responses, which represents the range of values in which the respondent's underlying true belief is plausibly deemed to lie based on the respondent's inferred rounding type. These intervals can be interpreted as a measure of informativeness, or quality, of an increasingly used type of data (numerical probabilistic expectations) from an important data source (the HRS).

Our approach accommodates substantial heterogeneity in rounding practices. Within a specific question domain, a respondent's rounding type is a bivariate vector of the form (tail, center) rounding, partitioning the 0-100 scale into two symmetric tails (0-24 and 76-100) and a center (25-75). Thus, in addition to being person specific, the inferred degree of rounding may differ between the tails and the center of the scale and may vary across question domains. The assigned intervals vary across respondents and across values of the observed point responses.

We use our framework to study how rounding tendencies vary with observable characteristics of the respondents. We find that higher levels of educational attainment and of cognition are associated with a 
tendency to give more refined responses (less rounding) across all scale segments and question domains. On the other hand, the association of rounding with age appears to be non-linear, with youngest (50-59) and oldest (80+) respondents displaying a higher tendency to round than respondents in the intermediate age groups (60-69 and 70-79).

These findings are substantively interesting, demonstrating systematic variation in how respondents answer expectations questions. They may also help to inform researchers working with other surveys that have less rich expectations data than the HRS. These researchers may know respondents' characteristics, but not have enough expectations data to apply our approach directly.

While this paper studies rounding as a subject of intrinsic interest, a reader may naturally ask how the interval data that our proposed approach generates from respondent point responses may be used in statistical analyses. In principle, empirical analysis with interval data is simply a matter of considering all points in the relevant interval to be feasible values of the quantity of interest. The practical feasibility of implementing this simple idea depends on the nature of the analysis. This matter has been addressed in the econometric literature studying conditional prediction with interval measurement of outcomes and/or covariates. See Manski and Tamer (2002) and Beresteanu and Molinari (2008). Manski and Molinari (2010) provide an illustrative application of best linear prediction with interval-measured expectations outcomes. Analogous applications to prediction with interval-measured covariates are feasible.

As far as we are aware, only two previous papers systematically study rounding of responses to probabilistic expectations questions. One is Manski and Molinari (2010), on whose work we build. The other is Kleinjans and van Soest (2014), who develop and estimate a panel-data structural econometric model to analyze response patterns to each of six expectations questions in the HRS. Their analysis aims to investigate the extent to which probability reports are determined by genuine underlying probabilistic beliefs, rounding, a tendency to give so-called "focal" responses of $(0,50,100)$, and selective item nonresponse. Despite the very different approaches taken, their findings and ours reinforce each other in 
some important respects. Specifically, they find that tendencies to round, give "focal" responses, and not respond tend to be persistent over time.

Beyond readers who have interest in expectations data, we anticipate that general statisticians concerned with survey research will find this paper useful. Our study of tendencies to round responses to expectations questions should heighten concern that respondents may round responses to numerical questions in other contexts. Consider, for example, questions asking respondents to state their income or the number of hours they worked in the past week. Respondents may round their responses, with the extent of rounding differing across persons. Examination of a person’s response pattern across different numerical questions, in the manner that we do here, may provide a credible way to infer that person's rounding practice. One may then interpret reported numerical values as intervals.

Some surveys elicit interval data directly. For example, the HRS uses unfolding bracket questions to enable respondents who are not willing to provide exact information about their income and assets to indicate whether the quantities of interest lie above or below a sequence of specified thresholds. Similarly, the Occupation Employment Statistics (Bureau of Labor Statistics, 2018) collects wage information in interval form. These intervals, too, can be analyzed using econometric methods for interval data referenced earlier.

Our interpretation of rounded responses as interval data provides an interesting counterpoint to previous statistical research on data coarsening. Rounded numerical responses have a different structure from the data analyzed in the literature on data coarsening (e.g., Heitjan and Rubin (1991), Heitjan (1994), and Gill et al. (1997)). In that literature, it is assumed that the researcher observes a random set $\mathscr{X}$ (an interval, a group, a partial categorization, etc.) to which an unobservable random variable of interest $x$ belongs with probability one. An assumption of “coarsening at random” is imposed, which requires that the probability of observing $\mathscr{X}=\mathrm{A}$ given $x=\mathrm{x}_{0}$ is constant for all $\mathrm{x}_{0}$ in $\mathrm{A}$, where A denotes a subset of the support of $x$. In contrast, the HRS does not provide set-valued expectations data. The algorithm that we propose constructs sets $\mathscr{X}$ based on respondents' point responses and their tendencies 
for rounding across the entire set of questions eliciting subjective beliefs. Our approach does not assume ignorability of the coarsening mechanism and it allows for a coarsening mechanism that differs among respondents.

\section{Exploratory Analysis of Response Patterns across Questions and Waves in the HRS}

Since 2002 the HRS has devoted Section P of its core questionnaire to measurement of expectations in the domains of personal health, personal finances, and general economic conditions. Across seven biannual waves spanning 2002 to 2014, expectations have been elicited on a 0-100 percent chance scale. Many questions have been repeated across multiple waves. Table 1 shows the questions, organized by domain and the waves in which they were asked.

Expectations questions in the HRS refer to future realizations of binary events. In some cases, respondents are asked to report the chance that the realization of a continuous variable will be above or below each of a sequence of thresholds. Answers to these questions can be used to measure a respondent's subjective distribution function for the variable in question. See Dominitz and Manski (1997) for an early example of elicitation and validation in this format.

The number of questions per wave ranges between a minimum of 22 in 2002 and a maximum of 38 in 2006. Most questions are in the personal finances domain (between 11 and 23 per wave, 31 overall), followed by the personal health domain (between 3 and 9 per wave, 10 overall), and the domain of general economic conditions (between 2 and 7 per wave, 12 overall). A subset of 12 questions across the three domains were asked in all waves.

The number of responses varies across questions and waves, ranging from about 5,000 to 30,000 responses per question in each wave. The variation across questions stems from the fact that the HRS makes extensive use of skip sequencing. Thus, whether a respondent is asked a specific question depends on the previous answers given by the respondent and on whether the event specified by the question is relevant to the respondent. 
Table 1: Probabilistic Expectations Questions in the HRS (Section P, Waves 2002-2014)

\begin{tabular}{|c|c|c|c|c|c|c|c|c|}
\hline \multirow[b]{2}{*}{ \# } & \multirow[b]{2}{*}{ Question } & \multicolumn{7}{|c|}{ Wave } \\
\hline & & 2002 & 2004 & 2006 & 2008 & 2010 & 2012 & 2014 \\
\hline \multicolumn{9}{|c|}{ PERSONAL HEALTH (3-9 Qs in each wave, 10 across waves) } \\
\hline P19 & Health limit work during next 10 years & $\mathrm{Y}$ & - & - & - & - & - & - \\
\hline P28 & Live to be 75 or more & $\mathbf{Y}$ & $\mathbf{Y}$ & $\mathbf{Y}$ & $\mathbf{Y}$ & $\mathbf{Y}$ & $\mathbf{Y}$ & $\mathbf{Y}$ \\
\hline P29 & Live to be age $\mathrm{X}$ or more & $\mathbf{Y}$ & $\mathbf{Y}$ & $\mathbf{Y}$ & $\mathbf{Y}$ & $\mathbf{Y}$ & $\mathbf{Y}$ & $\mathbf{Y}$ \\
\hline P32 & Move to nursing home ever (if age $<65$ ) / in the next 5 years (if age $>=65$ ) & $\mathbf{Y}$ & $\mathbf{Y}$ & $\mathbf{Y}$ & $\mathbf{Y}$ & $\mathbf{Y}$ & $\mathbf{Y}$ & $\mathbf{Y}$ \\
\hline P103 & Live independently at 75 & - & - & $\mathrm{Y}$ & $\mathrm{Y}$ & - & - & - \\
\hline P104 & Free of serious mental problems at 75 & - & - & $\mathrm{Y}$ & $\mathrm{Y}$ & - & - & - \\
\hline P106 & Live independently at X & - & - & $\mathrm{Y}$ & $\mathrm{Y}$ & - & - & - \\
\hline P107 & Free of serious problems in thinking/reasoning at $\mathrm{X}$ & - & - & $\mathrm{Y}$ & $\mathrm{Y}$ & - & $\mathrm{Y}$ & $\mathrm{Y}$ \\
\hline P108 & Same health in 4 years & - & - & $\mathrm{Y}$ & $\mathrm{Y}$ & - & - & - \\
\hline P109 & Worse health in 4 years & - & - & $\mathrm{Y}$ & $\mathrm{Y}$ & - & - & - \\
\hline \multicolumn{9}{|c|}{ PERSONAL FINANCES (11-23 Qs in each wave, 31 across waves) } \\
\hline P4 & Income keep up inflation for next 5 years & $\mathrm{Y}$ & $\mathrm{Y}$ & $\mathrm{Y}$ & - & - & - & - \\
\hline P5 & Leave inheritance $>=\$ 10,000$ & $\mathbf{Y}$ & $\mathbf{Y}$ & $\mathbf{Y}$ & $\mathbf{Y}$ & $\mathbf{Y}$ & $\mathbf{Y}$ & $\mathbf{Y}$ \\
\hline P6 & Leave inheritance $>=\$ 100,000$ & $\mathbf{Y}$ & $\mathbf{Y}$ & $\mathbf{Y}$ & $\mathbf{Y}$ & $\mathbf{Y}$ & $\mathbf{Y}$ & $\mathbf{Y}$ \\
\hline P7 & Leave any inheritance & $\mathbf{Y}$ & $\mathbf{Y}$ & $\mathbf{Y}$ & $\mathbf{Y}$ & $\mathbf{Y}$ & $\mathbf{Y}$ & $\mathbf{Y}$ \\
\hline P8 & Receive inheritance during next 10 years & $\mathrm{Y}$ & $\mathrm{Y}$ & $\mathrm{Y}$ & - & - & - & - \\
\hline P14 & Lose job next year & $\mathrm{Y}$ & $\mathrm{Y}$ & $\mathrm{Y}$ & - & $\mathrm{Y}$ & $\mathrm{Y}$ & $\mathrm{Y}$ \\
\hline P15 & Finding a job in few month in case of job-loss & $\mathrm{Y}$ & $\mathrm{Y}$ & $\mathrm{Y}$ & - & $\mathrm{Y}$ & $\mathrm{Y}$ & $\mathrm{Y}$ \\
\hline P16 & Working for pay in the future & $\mathbf{Y}$ & $\mathbf{Y}$ & $\mathbf{Y}$ & $\mathbf{Y}$ & $\mathbf{Y}$ & $\mathbf{Y}$ & $\mathbf{Y}$ \\
\hline P17 & Working full time after age 62 & $\mathbf{Y}$ & $\mathbf{Y}$ & $\mathbf{Y}$ & $\mathbf{Y}$ & $\mathbf{Y}$ & $\mathbf{Y}$ & $\mathbf{Y}$ \\
\hline P18 & Working full time after age 65 & $\mathbf{Y}$ & $\mathbf{Y}$ & $\mathbf{Y}$ & $\mathbf{Y}$ & $\mathbf{Y}$ & $\mathbf{Y}$ & $\mathbf{Y}$ \\
\hline P20 & Finding a job in few months if unemployed & $\mathbf{Y}$ & $\mathbf{Y}$ & $\mathbf{Y}$ & $\mathbf{Y}$ & $\mathbf{Y}$ & $\mathbf{Y}$ & $\mathbf{Y}$ \\
\hline P30 & Give $\$ 5,000$ to others over next 10 years & $\mathrm{Y}$ & $\mathrm{Y}$ & $\mathrm{Y}$ & - & - & - & - \\
\hline P31 & Receive $\$ 5,000$ from others over next 10 years & $\mathrm{Y}$ & $\mathrm{Y}$ & $\mathrm{Y}$ & - & - & - & - \\
\hline P59 & Leave inheritance $>=\$ 500,000$ & $\mathbf{Y}$ & $\mathbf{Y}$ & $\mathbf{Y}$ & $\mathbf{Y}$ & $\mathbf{Y}$ & $\mathbf{Y}$ & $\mathbf{Y}$ \\
\hline P70 & Medical expenses use up savings in next 5 years & - & $\mathrm{Y}$ & $\mathrm{Y}$ & $\mathrm{Y}$ & - & - & - \\
\hline P71 & Give $\$ 1,000$ to others during next 10 years & - & $\mathrm{Y}$ & $\mathrm{Y}$ & - & - & - & - \\
\hline P72 & Give $\$ 10,000$ to others during next 10 years & - & $\mathrm{Y}$ & $\mathrm{Y}$ & - & - & - & - \\
\hline P73 & Give $\$ 20,000$ to others during next 10 years & - & $\mathrm{Y}$ & $\mathrm{Y}$ & - & - & - & - \\
\hline P74 & Receive $\$ 2,500$ from others over next 10 years & - & $\mathrm{Y}$ & $\mathrm{Y}$ & - & - & - & - \\
\hline P75 & Receive $\$ 1,000$ from others over next 10 years & - & $\mathrm{Y}$ & $\mathrm{Y}$ & - & - & - & - \\
\hline P76 & Receive $\$ 10,000$ from others over next 10 years & - & $\mathrm{Y}$ & $\mathrm{Y}$ & - & - & - & - \\
\hline P111 & Soc. Sec. will be worse over next 10 years - current own benefits & - & - & $\mathrm{Y}$ & $\mathrm{Y}$ & $\mathrm{Y}$ & $\mathrm{Y}$ & $\mathrm{Y}$ \\
\hline P112 & Soc. Sec. will be worse over next 10 years - future own benefits & - & - & $\mathrm{Y}$ & $\mathrm{Y}$ & $\mathrm{Y}$ & $\mathrm{Y}$ & $\mathrm{Y}$ \\
\hline $\mathrm{P} 166$ & Home worth more by next year & - & - & - & - & $\mathrm{Y}$ & $\mathrm{Y}$ & $\mathrm{Y}$ \\
\hline $\mathrm{P} 168$ & Home worth more/less by random " $\mathrm{X}$ " by next year & - & - & - & - & $\mathrm{Y}$ & $\mathrm{Y}$ & $\mathrm{Y}$ \\
\hline $\mathrm{P} 175$ & Out-of-pocket medical expense $>\$ 1,500$ during next year & - & - & - & - & $\mathrm{Y}$ & $\mathrm{Y}$ & $\mathrm{Y}$ \\
\hline $\mathrm{P} 176$ & Out-of-pocket medical expense $>\$ 500$ during next year & - & - & - & - & $\mathrm{Y}$ & $\mathrm{Y}$ & $\mathrm{Y}$ \\
\hline P177 & Out-of-pocket medical expense $>\$ 3,000$ during next year & - & - & - & - & $\mathrm{Y}$ & $\mathrm{Y}$ & $\mathrm{Y}$ \\
\hline P178 & Out-of-pocket medical expense $>\$ 8,000$ during next year & - & - & - & - & $\mathrm{Y}$ & $\mathrm{Y}$ & $\mathrm{Y}$ \\
\hline P181 & Any work after age 70 & - & - & - & - & - & $\mathrm{Y}$ & $\mathrm{Y}$ \\
\hline P182 & Working full time after age 70 & - & - & - & - & - & $\mathrm{Y}$ & $\mathrm{Y}$ \\
\hline
\end{tabular}

GENERAL ECONOMIC CONDITIONS (2-7 Qs in each wave, 12 across waves)

\begin{tabular}{l|l}
\hline P34 & U.S. have economic depression during next 10 years \\
\hline
\end{tabular}

\begin{tabular}{|l|l|l}
\hline 47 & Mutual funds increase in value by next year \\
\hline
\end{tabular}

\begin{tabular}{|l|l} 
P110 & Social Security in general will become worse in next 10 years \\
\hline
\end{tabular}

P114 Mutual funds increase more than the cost of living over next 10 years

P115 Mutual funds increase $8 \%$ more than the cost of living over next 10 years

P116 Cost of living increases more than $5 \%$ over next 10 years

P150 Mutual funds increase by $20 \%$ (10\%, or a random X\%) by next year

P180 Mutual funds decrease by $20 \%$ by next year

P183 Medicare less generous in next 10 years

P190 Stock Market increase in value in 12 months of today

P192 2 Stock Market increse by 20\% (in 12 months)

P193 Stock Market decrease by 20\% (in 12 months)

Total N of Questions

\begin{tabular}{|c|c|c|c|c|c|c|}
\hline $\mathrm{Y}$ & $\mathrm{Y}$ & $\mathrm{Y}$ & $\mathrm{Y}$ & - & - & - \\
\hline $\mathbf{Y}$ & $\mathbf{Y}$ & $\mathbf{Y}$ & $\mathbf{Y}$ & $\mathbf{Y}$ & $\mathbf{Y}$ & $\mathbf{Y}$ \\
\hline $\mathrm{Y}$ & - & Y & $\mathrm{Y}$ & $\mathrm{Y}$ & $\mathrm{Y}$ & - \\
\hline- & - & $\mathrm{Y}$ & - & - & - & - \\
\hline- & - & $\mathrm{Y}$ & - & - & - & - \\
\hline- & - & $\mathrm{Y}$ & $\mathrm{Y}$ & - & - & - \\
\hline $\mathrm{Y}$ & - & - & $\mathrm{Y}$ & $\mathrm{Y}$ & $\mathrm{Y}$ & $\mathrm{Y}$ \\
\hline- & - & - & - & $\mathrm{Y}$ & $\mathrm{Y}$ & $\mathrm{Y}$ \\
\hline- & - & - & - & - & $\mathrm{Y}$ & $\mathrm{Y}$ \\
\hline- & - & - & - & - & - & $\mathrm{Y}$ \\
\hline- & - & - & - & - & - & $\mathrm{Y}$ \\
\hline- & - & - & - & - & - & $\mathrm{Y}$ \\
\hline 22 & 26 & 38 & 25 & 25 & 29 & 31 \\
\hline
\end{tabular}


The total number of responses generated by a question across the seven waves varies because questions have been added and removed over time. It also varies due to changes in sample composition across waves. The HRS sample has periodically been augmented with new cohorts of respondents who joined the study in specific waves. Respondents exit the study due to attrition or death.

Section 2.1 studies response patterns across questions in each wave, alternatively using all questions asked in the wave and the twelve questions asked in all waves. Focusing on the latter questions, we analyze the stability of response tendencies across pairs of waves. Supplementary Appendix 2.1 provides further detail, investigating patterns of response to specific questions.

Having established the temporal stability of rounding practices, Section 2.2 pools the HRS data across waves. This yields rich respondent-specific data that enables us to probe more deeply. We analyze response patterns separately by question domain. We pay particular attention to the location of responses inside the 0-100 scale and learn important features of respondents' response patterns in specific domains.

Throughout the paper, the notation $\mathbb{M} 10$ and $\mathbb{M} 5$ denotes responses that are multiples of 10 or 5 other than $(0,50,100)$. Thus, $\mathbb{M} 10 \equiv\{10,20,30,40,60,70,80,90\}$ and $\mathbb{M} 5 \equiv\{5,15,25,35,45,55$, $65,75,85,95\})$. When responses are non-rounded values - neither $(0,50,100)$ nor a multiple of 5 or 10 - we distinguish those in the outer tails of the scale, specifically 1-4 and 96-99, from those between 6 and 94. The abbreviation NR denotes nonresponse.

\subsection{Temporal Stability of Response Tendencies}

\subsubsection{Response Tendencies in Each Wave}

We first examine response tendencies in each HRS wave. Table 2 shows the fractions of respondents displaying each of seven mutually exclusive and exhaustive response patterns, progressing left to right from the most rounded to the least rounded. Column 3 gives the fraction of respondents who respond to no questions in the wave, coded in the HRS as “Don’t know” or "Refuse.” Column 4 gives the fraction 
of respondents who, when they respond, only use the values 0 and 100 in the corresponding wave. Column 5 gives the fraction who only use the values $(0,50,100)$. Columns 6 and 7 give the fractions of respondents who answer at least one question with a value in M10 and M5 respectively. Column 8 gives the fraction of respondents who respond to at least one question with a non-round value in the outer tails; that is, 1-4 or 96-99. Column 9, labelled "Some other," gives the fraction who respond at least once with a non-round value in the range 6-94.

The set of expectations questions varies across waves. The top panel of Table 2 presents a version of the statistics where respondents are classified into one of the seven response patterns using only the twelve questions that were asked in all seven waves (i.e., P5, P6, P7, P16, P17, P18, P20, P28, P29, P32, P47, P59). The bottom panel uses the responses to all questions asked in a wave.

A very small fraction of respondents answer none of the questions posed to them. This fraction ranges between 0.009 and 0.027 , depending on the set of questions used to classify respondents. Between 0.019 and 0.101 of respondents uses only the values $(0,100)$. Similar fractions of respondents use only the values $(0,50,100)$. Most respondents give at least one answer in $\mathbb{M} 10$ or in $\mathbb{M} 5$. The fraction of M10 respondents ranges between 0.263 and 0.337 across waves when all questions asked in a wave are used for classification and between 0.392 and 0.458 when only the questions common to all waves are used. Similarly, the fraction of $\mathbb{M} 5$ respondents ranges between 0.427 and 0.513 when all questions are used for classification and between 0.295 and 0.353 when only the common set is used.

The fractions of respondents who give at least one response in the outer tails (1-4 or 96-99) or nonrounded values in 6-94 are sizeable but considerably smaller, especially the latter. The former fraction ranges between 0.101 and 0.144 when all questions are used for classification and between 0.054 and 0.092 when only the common set is used. The latter fraction ranges between 0.022 and 0.042 or between 0.011 and 0.020 , depending on the set of questions used.

\subsubsection{Transitions of Response Tendencies across Waves}

The main message of Table 2 is that the response patterns found by Manski and Molinari (2010) in 
Table 2: Response Tendencies in the 2002-2014 HRS

\begin{tabular}{|c|c|c|c|c|c|c|c|c|}
\hline \multirow[b]{2}{*}{ Wave } & \multirow[b]{2}{*}{$\mathrm{N}$} & \multicolumn{7}{|c|}{ Response pattern } \\
\hline & & $\begin{array}{l}\text { All } \\
\text { NR }\end{array}$ & $\begin{array}{c}\text { All } 0 \\
\text { or } 100\end{array}$ & $\begin{array}{c}\text { All } 0,50 \text {, } \\
\text { or } 100\end{array}$ & $\begin{array}{l}\text { Some } \\
\text { M10 }\end{array}$ & $\begin{array}{l}\text { Some } \\
\text { M5 }\end{array}$ & $\begin{array}{c}\text { Some } 1-4 \\
\text { or } 96-99\end{array}$ & $\begin{array}{l}\text { Some } \\
\text { other }\end{array}$ \\
\hline \multicolumn{9}{|c|}{ Based on the 12 questions asked in all waves } \\
\hline 2002 & 16032 & 0.022 & 0.101 & 0.101 & 0.392 & 0.320 & 0.054 & 0.011 \\
\hline 2004 & 18250 & 0.015 & 0.062 & 0.084 & 0.418 & 0.353 & 0.056 & 0.013 \\
\hline 2006 & 17191 & 0.027 & 0.072 & 0.077 & 0.409 & 0.336 & 0.065 & 0.014 \\
\hline 2008 & 16060 & 0.021 & 0.068 & 0.063 & 0.417 & 0.340 & 0.072 & 0.018 \\
\hline 2010 & 20400 & 0.010 & 0.053 & 0.050 & 0.426 & 0.350 & 0.092 & 0.020 \\
\hline 2012 & 19360 & 0.015 & 0.051 & 0.058 & 0.445 & 0.328 & 0.083 & 0.020 \\
\hline 2014 & 17647 & 0.012 & 0.065 & 0.062 & 0.458 & 0.295 & 0.090 & 0.018 \\
\hline \multicolumn{9}{|c|}{ Based on all questions asked in each wave } \\
\hline 2002 & 16032 & 0.014 & 0.023 & 0.039 & 0.324 & 0.459 & 0.119 & 0.022 \\
\hline 2004 & 18250 & 0.010 & 0.019 & 0.032 & 0.337 & 0.467 & 0.108 & 0.026 \\
\hline 2006 & 17191 & 0.025 & 0.019 & 0.023 & 0.263 & 0.513 & 0.117 & 0.039 \\
\hline 2008 & 16060 & 0.021 & 0.025 & 0.019 & 0.290 & 0.511 & 0.101 & 0.033 \\
\hline 2010 & 20400 & 0.009 & 0.029 & 0.022 & 0.316 & 0.442 & 0.144 & 0.038 \\
\hline 2012 & 19360 & 0.014 & 0.027 & 0.021 & 0.317 & 0.443 & 0.139 & 0.038 \\
\hline 2014 & 17647 & 0.012 & 0.026 & 0.022 & 0.329 & 0.427 & 0.142 & 0.042 \\
\hline
\end{tabular}

NOTE: $\mathrm{N}=$ sample size, $\mathrm{NR}=$ nonresponse, $\mathbb{M} 10$ = multiple of 10 but not $(0,50,100)$, M5 = multiple of 5 but not of 10. The following 12 questions were asked in all HRS waves between 2002 and 2014: P47: mutual fund increase in value; P28: live to be 75 or more; P29: live to be X or more; P5: live inheritance $\geq \$ 10,000$; P6: live inheritance $\geq \$ 100,000$; P59: live inheritance $\geq \$ 500,000$; P7: leave any inheritance; P16: work for pay in the future; P17: work full time after age 62; P18: work full time after age 65; P32: move to nursing home in 5 years; P20: finding a job in few months if unemployed.

the 2006 wave of the HRS hold throughout the seven waves between 2002 and 2014. However, these are aggregate patterns that may partly be susceptible to variation across wave in sample composition. To address this issue, we compute transition matrices of response tendencies across waves. Specifically, for each pair of waves indicated by column, Table 3 reports the fractions of respondents classified as belonging to any rounding category in the first wave who transitioned to the same rounding category in the second wave $\left(1^{\text {st }}\right.$ row), who transitioned to a finer or coarser adjacent category ( $2^{\text {nd }}$ row), and who transitioned to a more distant rounding category ( $3^{\text {th }}$ row). The reported calculations use the twelve questions in common to the seven waves to classify respondents.

We find that between 0.406 and 0.436 of the respondents remain in the same rounding category across any pair of adjacent waves. Between 0.373 and 0.386 transition to an adjacent category. Thus, between 0.788 and 0.813 of the respondents transition to the same or an adjacent category. Even transitions between the first and last waves, with fourteen years separating them, display high 
Table 3: Transitions of Response Tendencies across Waves

\begin{tabular}{lcccccc|c}
\hline \multirow{2}{*}{ Transition waves: } & $\begin{array}{c}2002 \\
\text { to 2004 }\end{array}$ & $\begin{array}{c}2004 \\
\text { to 2006 }\end{array}$ & $\begin{array}{c}2006 \\
\text { to 2008 }\end{array}$ & $\begin{array}{c}2008 \\
\text { to 2010 }\end{array}$ & $\begin{array}{c}2010 \\
\text { to 2012 }\end{array}$ & $\begin{array}{c}2012 \\
\text { to 2014 }\end{array}$ & $\begin{array}{c}2002 \\
\text { to 2014 }\end{array}$ \\
\cline { 2 - 8 } \% transitions to: & \multicolumn{7}{c}{ Frequency (based on the 12 questions asked in all waves) } \\
\cline { 2 - 9 } same category & 0.406 & 0.420 & 0.406 & 0.415 & 0.436 & 0.433 & 0.389 \\
adjacent category & 0.386 & 0.383 & 0.383 & 0.385 & 0.377 & 0.373 & 0.392 \\
more distant category & 0.209 & 0.197 & 0.212 & 0.201 & 0.187 & 0.194 & 0.218 \\
\hline $\mathrm{N}(100 \%)$ & 14183 & 16126 & 15231 & 13732 & 18260 & 16923 & 8348 \\
\hline same or adjacent & 0.792 & 0.803 & 0.788 & 0.800 & 0.813 & 0.806 & 0.782 \\
\hline
\end{tabular}

NOTE: The percentages shown in the table are calculated from transition matrices of response tendencies defined in terms of the following categories: All NR, All $(0,100)$, All $(0,50,100)$, Some $\mathbb{M} 10$, Some M5, Some 1-4 or 96-99, Some other. The following 12 questions were asked in all HRS waves between 2002 and 2014: P47: mutual fund increase in value; P28: live to be 75 or more; P29: live to be $\mathrm{X}$ or more; P5: live inheritance $\geq$ $\$ 10,000$; P6: live inheritance $\geq \$ 100,000$; P59: live inheritance $\geq \$ 500,000$; P7: leave any inheritance; P16: work for pay in the future; P17: work full time after age 62; P18: work full time after age 65; P32: move to nursing home in 5 years; P20: finding a job in few months if unemployed.

persistence, with over 0.78 of the respondents transitioning to the same or an adjacent category.

The amount of temporal stability observed in Table 3 is remarkable. This is particularly true given the criteria used to classify respondents to this point. For example, consider a respondent whose most refined answer in 2002 is a multiple of 10 percent other than $(0,50,100)$ and who is thus classified as “Some M10.” If, in 2004, the same respondent were observed to give a single answer that is a multiple of 5 percent but not of 10 percent, he would be now classified as "Some M5."

\subsection{Pooling Data across Waves to Probe More Deeply into Response Tendencies}

With temporal stability established, we henceforth pool the HRS data across waves. This greatly increases the number of expectations responses observed per respondent, multiplying it sevenfold for respondents interviewed in all waves between 2002 and 2014. Across all questions and waves, the average number of responses per respondent is 106.8. By domain, this figure ranges from 19.1 for personal health to 66 for personal finances. With such rich respondent-specific data, we can probe more deeply into rounding practices than Manski and Molinari (2010) were able to with the 2006 wave alone. 
To obtain further insight, we scrutinized the rounding behavior of 100 respondents drawn at random. We found two highly interesting patterns. First, a substantial fraction of respondents round more coarsely in the center of the $0-100$ scale than in the tails. Second, respondents tend to use the percentchance values 25 and 75 more than they do other values ending in 5. Supplementary Appendix 2.2 describes the analysis underlying these findings.

Our study of 100 randomly drawn respondents does not reveal how prevalent the discovered features are across the whole sample of HRS respondents. To answer this question, we now refine our earlier categorization of rounding patterns. We define the center (C) of the percent-chance scale to be values in the range 26-74 and the tails (T) to be values in the ranges 0-24 and 76-100. The values 25 and 75 form the boundary between the tail and center. We group responses into nine categories, defined by their presence in $\mathrm{T}$ or $\mathrm{C}$ and by the degree to which they are multiples of smaller numbers. The categories are: $\mathbb{M} 1-\mathrm{T} \equiv$ values in 1-24 or 76-99 that are not multiples of 5; M1-C $\equiv$ values in 26-74 that are not multiples of 5; $\mathbb{M} 5-T \equiv\{5,15,85,95\} ; \mathbb{M} 5-C \equiv\{35,45,55,65\} ; \mathbb{M} 10-T \equiv\{10,20,80,90\}$; $\mathbb{M} 10-C \equiv\{30,40,60,70\} ; \mathbb{M} 25 \equiv\{25,75\} ; \mathbb{M} 100 \equiv\{0,100\} ; \mathbb{M} 50 \equiv\{50\}$.

With this categorization, Table 4 shows the distribution of responses across respondents for each question asked in Section P between 2002 and 2014. The two main features detected by inspecting the random sample are decisively confirmed in the general HRS sample. Comparison of the frequencies of M25 responses (in column 5) with the frequencies of the remaining M5 responses (M5-C in column 9 and M5-T in column 8) reveals that the fraction of $\{25,75\}$ responses is always higher than the fraction of responses ending in 5 in the center of the scale; that is, responses in $\{35,45,55,65\}$. For most questions across the three domains, the fraction of $\{25,75\}$ responses is higher than the fraction of responses ending in 5 in the tails of the scale; that is, responses in $\{5,15,85,95\}$.

Even more striking is comparison of the frequencies of responses in the tails of the scale versus those in the center. The fractions of $\mathbb{M} 10, \mathbb{M} 5$, and $\mathbb{M} 1$ responses in the tails are higher than the corresponding fractions of $\mathbb{M} 10, \mathbb{M} 5$, and $\mathbb{M} 1$ responses in the center for nearly all questions in Table 4. 
The only exceptions are questions P47 and P190, for which the fractions of $\mathbb{M} 10$-C responses are slightly higher than the fractions of M10-T responses.

\section{Transforming Expectations Responses into Interval Data}

The analysis of Section 2 reveals that HRS respondents differ systematically in their rounding practices, with a relatively small fraction habitually performing gross rounding and the majority sometimes giving more refined responses. We have established that the response tendencies are stable across waves. Furthermore, we have detected two patterns of responses that the earlier analysis by Manski and Molinari (2010) could not detect using only the 2006 data. One pattern is a relatively frequent use of 25 and 75 percent. The other is systematic use of more refined responses in the tails of the scale than in its center.

Table 4: Responses by Question and across Waves in the 2002-2014 HRS

\begin{tabular}{|c|c|c|c|c|c|c|c|c|c|c|c|}
\hline \multirow{2}{*}{ Question: percent chance that... } & \multirow{2}{*}{$\begin{array}{c}\mathrm{N} \\
\text { total } \\
\text { obs. }\end{array}$} & \multicolumn{10}{|c|}{ Percentage of responses in: } \\
\hline & & NR & M50 & M100 & M25 & $\begin{array}{c}\mathrm{M} 10 \\
\mathrm{~T}\end{array}$ & M10 & M5 & M5 & $\mathrm{M} 1$ & M1 \\
\hline & \multicolumn{11}{|c|}{ Personal Health } \\
\hline P28: Live to be age 75 or more & 56497 & 0.038 & 0.219 & 0.204 & 0.082 & 0.270 & 0.120 & 0.042 & 0.010 & 0.013 & 0.001 \\
\hline P29: Live to be age $\mathrm{X}$ or more & 118404 & 0.050 & 0.211 & 0.191 & 0.075 & 0.236 & 0.156 & 0.049 & 0.013 & 0.018 & 0.001 \\
\hline P32: Move to nursing home in $5 \mathrm{y}$ & 74696 & 0.059 & 0.120 & 0.426 & 0.039 & 0.206 & 0.062 & 0.060 & 0.003 & 0.023 & 0.001 \\
\hline P106: & 15291 & 0.060 & 0.219 & 0.144 & 0.100 & 0.234 & 0.166 & 0.046 & 0.015 & 0.015 & 0.001 \\
\hline hink/reason... & 33518 & 0.062 & 0.227 & 0.135 & 0.088 & 0.229 & 0.179 & 0.049 & 0.014 & 0.016 & 0.001 \\
\hline P108: Same health in 4 years & 16253 & 0.048 & 0.226 & 0.151 & 0.097 & 0.263 & 0.151 & 0.044 & 0.009 & 0.010 & 0.001 \\
\hline \multirow[t]{2}{*}{ P109: Worse health in 4 years } & 16232 & 0.069 & 0.228 & 0.146 & 0.077 & 0.272 & 0.143 & 0.043 & 0.008 & 0.014 & 0.001 \\
\hline & \multicolumn{11}{|c|}{ General Economic Conditions } \\
\hline P34: & 50661 & 0.069 & 0.234 & 0.148 & 0.083 & 0.228 & 0.170 & 0.041 & 0.014 & 0.011 & 0.001 \\
\hline P116: Cost living up /more than 5\% & 32431 & 0.077 & 0.151 & 0.210 & 0.089 & 0.252 & 0.152 & 0.045 & 0.010 & 0.013 & 0.001 \\
\hline P150: Mutual funds up by $20 / 10 / \mathrm{X} \%$ & 42092 & 0.034 & 0.156 & 0.090 & 0.070 & 0.314 & 0.237 & 0.063 & 0.017 & 0.018 & 0.002 \\
\hline P180: & 31658 & 0.019 & 0.179 & 0.098 & 0.061 & 0.318 & 0.225 & 0.064 & 0.017 & 0.016 & 0.002 \\
\hline P183: Medicare less generous in $10 \mathrm{y}$ & 36524 & 0.039 & 0.219 & 0.216 & 0.075 & 0.246 & 0.150 & 0.032 & 0.008 & 0.014 & 0.001 \\
\hline P190: Stock market up by next year & 8615 & 0.077 & 0.335 & 0.090 & 0.058 & 0.185 & 0.202 & 0.026 & 0.011 & 0.016 & 0.001 \\
\hline P192: Stock market up by $20 \%$ & 5430 & 0.021 & 0.151 & 0.108 & 0.054 & 0.342 & 0.199 & 0.084 & 0.012 & 0.028 & 0.001 \\
\hline P193: Stock market down by $20 \%$ & 5306 & 0.013 & 0.183 & 0.115 & 0.048 & 0.314 & 0.210 & 0.076 & 0.012 & 0.026 & 0.002 \\
\hline
\end{tabular}


Table 4 (Continued): Responses by Question and across Waves in the 2002-2014 HRS

\begin{tabular}{|c|c|c|c|c|c|c|c|c|c|c|c|}
\hline \multirow[b]{3}{*}{ Question: percent chance that... } & \multirow{3}{*}{$\begin{array}{c}\mathrm{N} \\
\text { total } \\
\text { obs. }\end{array}$} & \multicolumn{10}{|c|}{ Percentage of responses in: } \\
\hline & & \multirow[t]{2}{*}{ NR } & \multirow[t]{2}{*}{ M50 } & \multirow[t]{2}{*}{$\mathbb{M} 100$} & \multirow{2}{*}{\multicolumn{2}{|c|}{$\begin{array}{cc}\text { M25 } & \text { M10 } \\
\text { C } & \text { T } \\
\end{array}$}} & \multirow{2}{*}{$\begin{array}{c}\text { M10 } \\
\text { C }\end{array}$} & \multirow{2}{*}{$\begin{array}{c}\text { M5 } \\
\text { T }\end{array}$} & \multirow{2}{*}{$\begin{array}{c}\text { M5 } \\
\text { C }\end{array}$} & \multirow{2}{*}{$\begin{array}{c}\mathrm{M} 1 \\
\mathrm{~T}\end{array}$} & \multirow{2}{*}{$\begin{array}{c}\text { M1 } \\
\text { C }\end{array}$} \\
\hline & & & & & & & & & & & \\
\hline & & & & & Pers & Ial Fina & & & & & \\
\hline P4: Income keep up inflation in $5 \mathrm{y}$ & 51559 & 0.066 & 0.196 & 0.226 & 0.069 & 0.249 & 0.136 & 0.036 & 0.007 & 0.015 & 0.001 \\
\hline P5: Leave inheritance $\geq \$ 10 \mathrm{~K}$ & 116769 & 0.046 & 0.083 & 0.518 & 0.028 & 0.228 & 0.051 & 0.028 & 0.001 & 0.017 & 0.000 \\
\hline P6: Leave inheritance $\geq \$ 100 \mathrm{~K}$ & 95625 & 0.014 & 0.100 & 0.490 & 0.037 & 0.228 & 0.072 & 0.035 & 0.002 & 0.022 & 0.000 \\
\hline P7: Leave any inheritance & 19716 & 0.020 & 0.053 & 0.763 & 0.013 & 0.098 & 0.021 & 0.020 & 0.001 & 0.012 & 0.000 \\
\hline P8: Receive inheritance in $10 \mathrm{y}$ & 51559 & 0.032 & 0.043 & 0.755 & 0.016 & 0.091 & 0.024 & 0.023 & 0.001 & 0.014 & 0.000 \\
\hline P14: Lose job next year & 32743 & 0.017 & 0.129 & 0.405 & 0.028 & 0.261 & 0.060 & 0.067 & 0.003 & 0.031 & 0.000 \\
\hline P15: Find job in few months/loss & 32727 & 0.015 & 0.158 & 0.276 & 0.056 & 0.287 & 0.128 & 0.053 & 0.004 & 0.022 & 0.000 \\
\hline P16: Work for pay in the future & 66855 & 0.018 & 0.055 & 0.672 & 0.021 & 0.139 & 0.037 & 0.035 & 0.001 & 0.021 & 0.000 \\
\hline P17: Work full time after age 62 & 36603 & 0.011 & 0.144 & 0.333 & 0.055 & 0.268 & 0.120 & 0.043 & 0.006 & 0.020 & 0.001 \\
\hline P18: Work full time after age 65 & 37062 & 0.011 & 0.144 & 0.280 & 0.058 & 0.282 & 0.130 & 0.057 & 0.008 & 0.028 & 0.001 \\
\hline P20: Find job in few months/unemployed & 8206 & 0.012 & 0.211 & 0.184 & 0.061 & 0.277 & 0.174 & 0.050 & 0.012 & 0.019 & 0.001 \\
\hline P30: Give $\$ 5 \mathrm{~K}$ to others in $10 \mathrm{y}$ & 50528 & 0.024 & 0.120 & 0.505 & 0.050 & 0.187 & 0.065 & 0.035 & 0.002 & 0.011 & 0.000 \\
\hline P31: Receive $\$ 5 \mathrm{~K} \ldots$ in $10 \mathrm{y}$ & 50528 & 0.023 & 0.047 & 0.674 & 0.020 & 0.143 & 0.026 & 0.047 & 0.001 & 0.019 & 0.000 \\
\hline P59: Leave inheritance $\geq \$ 500 \mathrm{~K}$ & 73872 & 0.011 & 0.090 & 0.490 & 0.034 & 0.216 & 0.073 & 0.046 & 0.003 & 0.037 & 0.000 \\
\hline P70: Med expenses & 50478 & 0.060 & 0.141 & 0.316 & 0.060 & 0.246 & 0.109 & 0.048 & 0.006 & 0.014 & 0.000 \\
\hline P71: Give $\$ 1 \mathrm{~K}$ to others in $10 \mathrm{y}$ & 21024 & 0.007 & 0.097 & 0.551 & 0.044 & 0.186 & 0.060 & 0.041 & 0.002 & 0.013 & 0.000 \\
\hline P72: Give $\$ 10 \mathrm{~K}$ to others in $10 \mathrm{y}$ & 12904 & 0.011 & 0.212 & 0.322 & 0.072 & 0.219 & 0.124 & 0.026 & 0.006 & 0.007 & 0.001 \\
\hline P73: Give $\$ 20 \mathrm{~K}$ to others in $10 \mathrm{y}$ & 11155 & 0.011 & 0.152 & 0.334 & 0.061 & 0.265 & 0.100 & 0.057 & 0.005 & 0.015 & 0.000 \\
\hline P74: Receive $\$ 2.5 \mathrm{~K} \ldots$ in $10 \mathrm{y}$ & 30644 & 0.004 & 0.021 & 0.723 & 0.019 & 0.134 & 0.023 & 0.053 & 0.001 & 0.022 & 0.000 \\
\hline $\mathrm{K} \ldots$ in $10 \mathrm{y}$ & 30397 & 0.003 & 0.042 & 0.686 & 0.024 & 0.141 & 0.031 & 0.051 & 0.001 & 0.021 & 0.000 \\
\hline P76: Receive $\$ 10 \mathrm{~K} \ldots$ in $10 \mathrm{y}$ & 3270 & 0.015 & 0.243 & 0.321 & 0.052 & 0.198 & 0.134 & 0.022 & 0.009 & 0.006 & 0.001 \\
\hline P111: SS worse/current own benefits & 51023 & 0.036 & 0.246 & 0.197 & 0.080 & 0.246 & 0.138 & 0.037 & 0.007 & 0.012 & 0.001 \\
\hline P112: SS worse/future own benefits & 26753 & 0.020 & 0.205 & 0.186 & 0.085 & 0.255 & 0.179 & 0.040 & 0.014 & 0.014 & 0.001 \\
\hline P166: Home worth more next year & 28067 & 0.030 & 0.202 & 0.165 & 0.045 & 0.361 & 0.146 & 0.033 & 0.005 & 0.011 & 0.001 \\
\hline P168: Home worth more/less by X & 26394 & 0.035 & 0.112 & 0.259 & 0.029 & 0.348 & 0.120 & 0.070 & 0.004 & 0.024 & 0.000 \\
\hline P175: OP med exp $\geq \$ 1.5 \mathrm{~K}$ next year & 56760 & 0.031 & 0.143 & 0.340 & 0.051 & 0.261 & 0.109 & 0.043 & 0.004 & 0.017 & 0.000 \\
\hline P176: OP med exp $\geq \$ 500$ next year & 10962 & 0.017 & 0.114 & 0.642 & 0.025 & 0.126 & 0.043 & 0.020 & 0.001 & 0.012 & 0.000 \\
\hline P177: OP med exp $\geq \$ 3 \mathrm{~K}$ next year & 44022 & 0.012 & 0.132 & 0.235 & 0.058 & 0.318 & 0.126 & 0.082 & 0.006 & 0.033 & 0.000 \\
\hline P178: OP med exp $\geq \$ 8 K$ next year & 36369 & 0.009 & 0.079 & 0.260 & 0.037 & 0.327 & 0.092 & 0.120 & 0.005 & 0.071 & 0.000 \\
\hline P181: Any work after age 70 & 17057 & 0.010 & 0.118 & 0.374 & 0.042 & 0.259 & 0.101 & 0.058 & 0.005 & 0.034 & 0.000 \\
\hline P182: Work full time after age 70 & 10384 & 0.003 & 0.100 & 0.264 & 0.038 & 0.323 & 0.108 & 0.097 & 0.007 & 0.060 & 0.000 \\
\hline
\end{tabular}

NOTE: $\mathbb{M} 50 \equiv\{50\}, \mathbb{M} 100 \equiv\{0,100\}, \mathbb{M} 25 \equiv\{25,75\}, \mathbb{M} 10-\mathrm{T} \equiv\{10,20,80,90\}, \mathbb{M} 10-\mathrm{C} \equiv\{30,40,60,70\}, \mathbb{M} 5-\mathrm{T} \equiv\{5,15,85$ 95 $\}$, M5-C $\equiv\{35,45,55,65\}, \mathbb{M} 1-\mathrm{T} \equiv$ non-round values in 1-24 or 76-99, M1-C $\equiv$ non-round values in 26-74.

Generalizing the inferential approach proposed by Manski and Molinari (2010), this section develops a new algorithm that uses the response tendency of a respondent to characterize rounding of responses to particular questions. The algorithm classifies each respondent into one of a set of mutually exclusive and exhaustive rounding types and transforms each original point response into an interval where the true latent belief is deemed to lie. With this accomplished, statistical analyses of expectations may proceed using the intervals thus constructed in place of the observed point responses.

Our algorithm relies on considerably weaker and more credible assumptions than inference that uses expectations reports at face value. Nevertheless, we cannot be certain that the intervals we construct are 
accurate. The algorithm is subject to two potential forms of misclassification. First, a given survey response may be less rounded than the interval assigned by the algorithm; that is, the actual rounding interval may be a subset of the algorithm's interval. Then our use of the data is correct, but it yields inference that is less sharp than it would be if the true degree of rounding were known. Second, the actual rounding interval may not be completely contained in the algorithm's interval. Then the actual belief may lie outside our interval, making our use of the data incorrect. Still, use of the algorithm substantially lowers the risk of the latter type of error relative to the standard approach that takes survey responses at face value.

The new algorithm embodies the data patterns documented in Section 2. Section 3.1 describes the determination of a respondent's rounding type. Section 3.2 presents the empirical distribution of the respondents' inferred rounding types and studies how rounding tendencies vary with observed characteristics of the respondents. Section 3.3 explains how a respondent's point response to a specific question and the respondent's inferred rounding type are used to construct the interval associated with the observed point response.

\subsection{Determination of Respondent Rounding Types}

Based on the evidence in Section 2, we allow a respondent's rounding type to vary across question domains and between the tails and center of the measurement scale. Thus, within a specific domain of questions, a respondent's rounding type is a bivariate vector of the form (tail, center) rounding, partitioning the 0-100 scale into two symmetric tails (0-24 and 76-100) and a center (25-75). We believe that our specific choice of tails and center reasonably reflects the empirical patterns of HRS responses, but judgments need not be uniform. The algorithm can be easily adapted to different definitions of tails and center or extended to accommodate finer partitions of the 0-100 scale (e.g., outer tails, inner tails, center). 
The new algorithm refines the earlier one posed by Manski and Molinari (2010) in multiple ways. One refinement is to separate tail from center rounding. Another is to classify persons who only use the response values $(0,25,50,75,100)$ as rounding to the nearest 25 percent rather than to the nearest 5 percent. A further difference between the two algorithms is that here we use a tighter criterion for assignment of a person to a more refined rounding type.

To explain the tighter criterion, consider categorization of a respondent as one who rounds to the nearest 10 percent (or to a more refined degree). Manski and Molinari assigned a respondent to this rounding type if all responses are multiples of 10 and at least one response is not a value in $(0,50,100)$. We use here a tighter criterion that requires observation of at least two responses that are multiples of 10 other than $(0,50,100)$, of which one must be in the domain under consideration and the other may be in a different domain and may also be a less rounded response; that is, a value that is not a multiple of 10 .

Adding the new requirement reflects our desire for further credibility when assigning a person to a more refined rounding type. We want enhanced credibility because misclassification into an overly refined rounding category yields an inferential error, as the person's latent beliefs may not entirely lie within the overly refined interval. Misclassification of a person into a rounding category less refined than their actual one does not yield an inferential error, as the less refined interval includes the actual one as a subset.

The main criteria for classification of respondents are as follows:

- Center rounding type Define $x_{n}$ in $\{1,5,10,50\}$, with $n=1, \ldots, 4$. Respondent $j$ is classified as rounding to the nearest $x_{n}$ percent in the center within question domain $l$ if one of the following two conditions holds: (i) they are observed to give at least two answers in the center that are multiples of $x_{n}$ percent but not of $x_{n^{\prime}}$ for any $n^{\prime}<n \underline{\text { within domain } l \text {; or (ii) they are observed to give one answer }}$

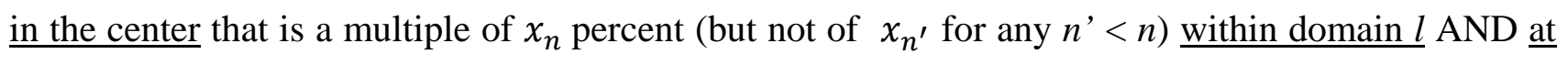
least one answer in the center that is a multiple of $x_{n^{\prime}}$ for any $n^{\prime} \leq n$ within a second domain $l^{\prime}$ distinct from $l$. 
- Tail rounding type Respondent $j$ is classified as rounding to the nearest $x_{n}$ percent in the tails within question domain $l$ if one of the following two conditions holds: (i) they are observed to give

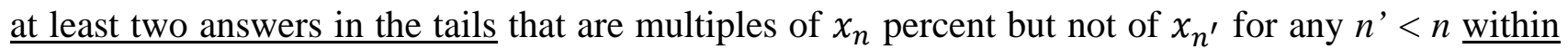
domain l; or (ii) they are observed to give one answer in the tails that is a multiple of $x_{n}$ percent (but not of $x_{n^{\prime}}$ for any $n^{\prime}<n$ ) within domain $l$ AND at least one answer in the tails OR center that is a multiple of $x_{n^{\prime}}$ for any $n^{\prime} \leq n$ within a second domain l' distinct from $l$.

To illustrate, consider a respondent who has answered four expectations questions in the domain of personal finances, either within the same wave or over multiple waves. Two of the observed responses belong to the tails, $\{5,85\}$, and two to the center, $\{30,60\}$. As the set of responses includes two multiples of 5 percent in the tails and two multiples of 10 percent in the center, our algorithm classifies this respondent as one rounding to the nearest 5 percent, or to a finer degree, in the tails ( $\mathcal{M} 5$-T) and to the nearest 10 percent, or to a finer degree, in the center ( $\mathcal{M} 10-\mathrm{C})$.

In this example, our algorithm reaches conclusions that differ in important ways from those of the Manski and Molinari (2010) algorithm. Application of that algorithm would classify this respondent as rounding to the nearest 5 percent, or to a finer degree, everywhere within the personal finances domain. Equivalently, given that the Manski-Molinari algorithm does not allow for differential rounding between tails and center, it would classify the hypothesized respondent as ( $\mathcal{M} 5$ - $\mathrm{T}, \boldsymbol{\mathcal { M }}$ 5-C). Using our algorithm, the evidence generated by the respondent's response pattern across questions classifies the respondent as ( $\mathcal{M} 5$-T, $\boldsymbol{M} 10-\mathrm{C})$, with a less refined rounding type in the center. This difference reflects our new finding that respondents tend to round more coarsely in the center than in the tails, which could not have been reached using a single wave of the HRS data.

The Supplementary Appendix 3.1 provides additional and more complex examples. It also presents the complete algorithm in a formal and compact way. 


\subsection{Empirical Distribution of Rounding Types and Association with Observable}

\section{Characteristics}

We apply the algorithm to all HRS respondents who responded to at least one expectations question in any question domain and in any wave between 2002 and 2014. Table 5 reports the empirical distribution of rounding types for each domain of questions. Depending on the domain, between $40.40 \%$ and $61.03 \%$ of respondents are inferred to apply finer rounding in the tails than in the center. Between $28.49 \%$ and $38.73 \%$ of respondents apply the same degree of rounding in the tails and in the center. Between $2.90 \%$ and $6.71 \%$ of respondents apply coarser rounding in the tails than in the center.

The rounding type of a small minority of respondents could not be determined either in the tails or in the center or both. Most undetermined cases occur when, for a given respondent, we do not observe any answer in the relevant domain and scale segment. Among respondents for whom we observe at least one answer in the relevant domain and scale segment, all cases of undetermined tail rounding type disappear and only a few cases of undetermined center rounding type remain. The latter are respondents for whom we only observe one answer in the center in the relevant domain and no answers in the center in the remaining two domains.

We now investigate how rounding types vary with observable respondent characteristics. This exercise sheds some light on the heterogeneity of respondents' tendencies to round. In addition, it may inform researchers who analyze survey expectations in datasets other than the HRS. These researchers may know respondents' characteristics in their data sets, but not have enough expectations data to apply our proposed approach directly.

In principle, nonparametric regression of rounding type on respondent characteristics would give the most complete information on observable heterogeneity in tendencies to round. However, we distinguish twenty rounding types (4 tail categories times 5 center categories) and observe multiple respondent characteristics. This makes nonparametric regression too cumbersome to be appealing. A pragmatic 
Table 5: Distribution of Rounding Types by Domain

\begin{tabular}{|c|c|c|c|}
\hline Rounding Type & $\begin{array}{c}\text { Percent } \\
\text { Personal } \\
\text { Health }\end{array}$ & $\begin{array}{c}\text { Percent } \\
\text { Personal Finances }\end{array}$ & $\begin{array}{c}\text { Percent } \\
\text { General Economic } \\
\text { Conditions }\end{array}$ \\
\hline (M1-T, M1-C) & 0.17 & 0.33 & 0.26 \\
\hline (M1-T, M5-C) & 1.07 & 3.03 & 1.22 \\
\hline (M1-T, M10-C) & 6.08 & 15.84 & 5.73 \\
\hline (M1-T, M25) & 1.33 & 1.72 & 0.80 \\
\hline (M1-T, M50) & 1.27 & 1.31 & 0.86 \\
\hline (M1-T, None/Undet.) & 1.02 & 0.50 & 0.42 \\
\hline$(M 5-T, M 1-C)$ & 0.07 & 0.08 & 0.11 \\
\hline (M5-T, M5-C) & 2.60 & 2.97 & 3.65 \\
\hline (M5-T, M10-C) & 16.05 & 23.47 & 16.98 \\
\hline (M5-T, M25) & 3.20 & 2.95 & 2.29 \\
\hline (M5-T, M50) & 2.53 & 1.75 & 1.35 \\
\hline (M5-T, None/Undet.) & 1.39 & 0.53 & 0.55 \\
\hline$(M 10-T, M 1-C)$ & 0.13 & 0 & 0.16 \\
\hline$(M 10-T, M 5-C)$ & 1.84 & 0.73 & 2.47 \\
\hline (M10-T, M10-C) & 25.92 & 22.75 & 32.50 \\
\hline (M10-T, M25) & 5.91 & 5.09 & 5.24 \\
\hline (M10-T, M50) & 7.98 & 5.88 & 5.93 \\
\hline (M10-T, None/Undet.) & 4.35 & 2.36 & 2.70 \\
\hline$(M 100, M 1-C)$ & 0 & 0 & 0.01 \\
\hline$(M 100, M 5-C)$ & 0.16 & 0.03 & 0.14 \\
\hline$(M 100, M 10-C)$ & 2.89 & 1.04 & 1.96 \\
\hline$(M 100, M 25)$ & 1.62 & 1.01 & 1.08 \\
\hline$(M 100$, M50) & 3.90 & 2.45 & 2.32 \\
\hline (M100, None/Undet.) & 4.74 & 3.42 & 2.47 \\
\hline (None/Undet., M1-C) & 0.01 & 0 & 0.01 \\
\hline (None/Undet., M5-C) & 0.20 & 0.01 & 0.24 \\
\hline (None/Undet., M10-C) & 1.27 & 0.01 & 2.50 \\
\hline (None/Undet., M25) & 0.47 & 0.00 & 0.92 \\
\hline (None/Undet., M50) & 0.92 & 0 & 2.06 \\
\hline (None/Undet., None/Undet.) & 0.91 & 0.75 & 3.06 \\
\hline Total & 100 & 100 & 100 \\
\hline Sample size & 28044 & 28252 & 28172 \\
\hline Tails finer than center & 45.42 & 61.03 & 40.40 \\
\hline Tails same as center & 32.60 & 28.49 & 38.73 \\
\hline Tails coarser than center & 6.71 & 2.90 & 5.94 \\
\hline No/Undet. T and/or C & 15.27 & 7.58 & 14.93 \\
\hline
\end{tabular}

approach is to summarize the data using parametric bivariate ordered probit regression, which embodies the basic ordinal property that our rounding categories display across different degrees of rounding.

Table 6 presents estimated coefficients of three bivariate ordered probit regressions, one per question domain. The outcome variables are the respondent's bivariate vectors of tail and center rounding categories in each domain. As predictors, we use binary variables for respondent's gender (male, with 
female omitted), educational attainment (high school, some college, bachelor, and graduate, with less than high school omitted), and race (black and other, with white omitted).

We also include information on individual's age and cognitive functioning. While these variables are time-varying for each respondent, our analysis in Section 2.1.2 and 2.2 supports treating respondent rounding behavior as fixed over time. We therefore account for age variation across respondents by incorporating in our bivariate ordered probit regressions an indicator of whether each respondent's cross-wave average age lies in the categories 60-69, 70-79, and 80+ years, with 50-59 the omitted category. We account for variation in cognitive functioning across respondents by including each respondent's cross-wave average cognitive score. See Fisher et al. (2012) and Crimmins et al. (2011) for a description and an empirical assessment of the HRS cognitive measures.

The cognitive score has a range of 0-35. In our data, the respondent-specific cross-wave average cognitive score has a mean of 23 and a standard deviation of 4.11 across respondents. The respondentspecific cross-wave standard deviation in cognitive score has a mean of 2.9 across respondents. The fact that the standard deviation of the cross-wave average score is larger than the average cross-wave standard deviation in the score lessens our concerns for using a time-fixed measure of cognitive functioning in our bivariate ordered probit regressions. Nonetheless, the time variation in cognitive score and its association with rounding warrant study in future research.

The model permits the error terms of the latent variables underlying the inferred tail and center rounding categories to be correlated with each other. The correlation parameter, $\rho$, is estimated along with the other coefficients. The rounding categories are ordered from least coarse to most coarse. Thus, positive associations indicate a tendency to round more coarsely.

Formally, within each domain, the bivariate ordered probit model specifies two seemingly unrelated latent equations for the respondent's tendency to round, one for the tail and one for the center, where $y^{*, C}=X \beta^{C}+\varepsilon^{C}$ and $y^{*, T}=X \beta^{T}+\varepsilon^{T}$. The pair $\left(\varepsilon^{C}, \varepsilon^{T}\right)$ is assumed to have the standardized bivariate normal distribution with means zero, both variances equal to one, and correlation $\rho$. 
Table 6: Bivariate Ordered Probit Model Predicting Rounding Type

\begin{tabular}{|c|c|c|c|c|c|c|}
\hline & \multicolumn{2}{|c|}{ Personal Health } & \multicolumn{2}{|c|}{ Personal Finances } & \multicolumn{2}{|c|}{ Gen. Econ. Conditions } \\
\hline & Tail Type & Center Type & Tail Type & Center Type & Tail Type & Center Type \\
\hline \multirow[t]{2}{*}{ Male } & 0.0047 & -0.0497 & -0.0032 & -0.0154 & -0.0070 & -0.0693 \\
\hline & $(0.0149)$ & $(0.0155)$ & $(0.0142)$ & $(0.0153)$ & $(0.0151)$ & $(0.0157)$ \\
\hline \multirow[t]{2}{*}{ Age 60-69 } & -0.1961 & -0.1436 & -0.0116 & 0.0145 & -0.1090 & -0.1049 \\
\hline & $(0.0180)$ & $(0.0194)$ & $(0.0174)$ & (0.0189) & $(0.0185)$ & $(0.0195)$ \\
\hline \multirow[t]{2}{*}{ Age 70-79 } & -0.1639 & 0.0481 & 0.1466 & 0.1987 & -0.0941 & 0.0232 \\
\hline & (0.0199) & $(0.0206)$ & (0.0189) & $(0.0204)$ & (0.0199) & $(0.0208)$ \\
\hline \multirow[t]{2}{*}{ Age 80+ } & 0.1092 & 0.4465 & 0.4934 & 0.5658 & 0.1718 & 0.3209 \\
\hline & $(0.0266)$ & $(0.0261)$ & $(0.0246)$ & $(0.0258)$ & $(0.0266)$ & $(0.0266)$ \\
\hline \multirow[t]{2}{*}{ High school } & -0.0842 & -0.0864 & -0.1277 & -0.1579 & -0.0614 & -0.1115 \\
\hline & $(0.0224)$ & $(0.0221)$ & $(0.0208)$ & $(0.0219)$ & $(0.0226)$ & $(0.0227)$ \\
\hline \multirow[t]{2}{*}{ Some college } & -0.0642 & -0.0758 & -0.1688 & -0.1948 & -0.0588 & -0.1487 \\
\hline & $(0.0362)$ & $(0.0379)$ & $(0.0342)$ & $(0.0372)$ & $(0.0364)$ & $(0.0389)$ \\
\hline \multirow[t]{2}{*}{ Bachelor } & -0.2027 & -0.2432 & -0.2677 & -0.3073 & -0.1726 & -0.2692 \\
\hline & $(0.0288)$ & $(0.0301)$ & $(0.0277)$ & $(0.0296)$ & $(0.0292)$ & $(0.0305)$ \\
\hline \multirow[t]{2}{*}{ Graduate } & -0.2818 & -0.3658 & -0.3367 & -0.3549 & -0.2438 & -0.3454 \\
\hline & $(0.0319)$ & $(0.0337)$ & $(0.0307)$ & $(0.0332)$ & $(0.0320)$ & $(0.0341)$ \\
\hline \multirow[t]{2}{*}{ Black } & 0.0188 & 0.1148 & -0.1507 & -0.0798 & -0.0562 & -0.0456 \\
\hline & $(0.0220)$ & $(0.0226)$ & $(0.0203)$ & $(0.0220)$ & $(0.0219)$ & $(0.0228)$ \\
\hline \multirow[t]{2}{*}{ Other race } & 0.1136 & 0.1374 & 0.0604 & 0.0173 & 0.0887 & 0.0477 \\
\hline & $(0.0303)$ & $(0.0322)$ & (0.0289) & $(0.0310)$ & $(0.0314)$ & $(0.0322)$ \\
\hline \multirow[t]{2}{*}{ Avg. Cog. } & -0.0261 & -0.0339 & -0.0368 & -0.0373 & -0.0202 & -0.0370 \\
\hline & $(0.0022)$ & $(0.0023)$ & $(0.0020)$ & $(0.0022)$ & $(0.0022)$ & $(0.0023)$ \\
\hline \multirow[t]{2}{*}{ Rho } & \multirow{2}{*}{\multicolumn{2}{|c|}{$\begin{array}{c}0.2595 \\
(0.0081)\end{array}$}} & \multirow{2}{*}{\multicolumn{2}{|c|}{$\begin{array}{c}0.3848 \\
(0.0087)\end{array}$}} & \multirow{2}{*}{\multicolumn{2}{|c|}{$\begin{array}{c}0.2897 \\
(0.0093)\end{array}$}} \\
\hline & & & & & & \\
\hline $\mathbf{N}$ & \multicolumn{2}{|c|}{22,447} & \multicolumn{2}{|c|}{24,541} & \multicolumn{2}{|c|}{22,593} \\
\hline
\end{tabular}

NOTES: (i) Respondents with undetermined tail or center rounding type are excluded from this analysis. (ii) Predictors are dummies for gender, age (averaged across waves), education, and race, plus average cognition score across waves. (iii) Omitted dummies are 'Female,' 'Age in 50-59,' 'No degree,' and 'White.' (iv) 'Rho' is the parameter capturing the correlation between the error terms of the tail and center latent equations. (v) Standard errors are in parentheses.

For each $k=C, T$, the model assumes that respondent rounds to multiples of 1 if $y^{*, k}<\delta_{1}^{k}$, to multiples of 5 if $\delta_{1}^{k} \leq y^{*, k}<\delta_{2}^{k}$, and so on, for a total of four categories in the tails (M1-T, M15-T, M10- 
$\mathrm{T}, \mathbb{M} 100$ ) and five categories in the center (M1-C, M5-C, M10-C, M25, M50). It is then possible to obtain the likelihood function for the rounding types. For $l=1, \ldots, 5$ and $m=1, \ldots, 4$, the probability that a person has rounding type $(l, m)$ is

$$
\begin{gathered}
\operatorname{Pr}\left(y_{i}^{C}=l, y_{i}^{T}=m\right)=\Phi\left(\left(\delta_{l}^{C}-X \beta^{C}\right),\left(\delta_{m}^{T}-X \beta^{T}\right), \rho\right)-\Phi\left(\left(\delta_{l-1}^{C}-X \beta^{C}\right),\left(\delta_{m}^{T}-X \beta^{T}\right), \rho\right) \\
-\Phi\left(\left(\delta_{l}^{C}-X \beta^{C}\right),\left(\delta_{m-1}^{T}-X \beta^{T}\right), \rho\right)+\Phi\left(\left(\delta_{l-1}^{C}-X \beta^{C}\right),\left(\delta_{m-1}^{T}-X \beta^{T}\right), \rho\right)
\end{gathered}
$$

where $\Phi$ is the standardized bivariate normal distribution function with mean zero, both variances equal to one, and correlation $\rho$.

We estimate the parameters by maximum likelihood using the Stata package described in Sajaia (2008). The bivariate probit model and other multivariate discrete outcome models are discussed, for example, in Amemiya (1981). Estimated coefficients with standard errors are reported in Table 6. Table 7 reports predicted probabilities of selected tail and center rounding types for persons with specified covariate values.

We find that higher levels of educational attainment and of person-specific average (cross-wave) cognitive score are associated with a tendency to give more refined responses across all scale segments and question domains. The patterns for the other predictors are more varied.

For example, respondents in the oldest age category $\left(80^{+}\right)$tend to give more rounded responses than respondents belonging to the youngest one (50-59) across all scale segments and questions domains. On the other hand, respondents in the two intermediate age groups (i.e., 60-69 and 70-79) belong to rounding categories that may be more refined, coarser, or statistically indistinguishable from those characterizing younger respondents, depending on the specific domain or scale segment.

A potential interpretation of the observed age patterns is that individuals belonging to the intermediate age groups may have more direct experience and hence better knowledge of the topics covered by the questions than younger respondents, generating more refined responses among the middle groups. On the other hand, individuals of older age might already, on average, have lower 
cognitive functioning, leading to coarser responses. This pattern, however, continues to hold after conditioning on the respondent's average (across waves) cognitive score. Parameter estimates for a specification without cognitive score are shown in the Supplementary Appendix.

Male respondents tend to round more coarsely than female respondents in the personal health and personal finances domains, but only in the tails. On the other hand, male respondents tend to round less coarsely than women respondents in the center in the domain of general economic conditions. While respondents belonging to the residual race category (including Hispanic, Asian, and Pacific Islander) tend to round more coarsely than white respondents, the differential rounding tendencies of black respondents relative to white respondents vary across question domains and scale segments.

The large, positive, and statistically significant estimates of the correlation parameter $\rho$ reveal that rounding tendencies are positively correlated across scale segments. Hence, respondents who give coarser responses in the tails are more likely to do so in the center.

\subsection{Using Survey Responses and Rounding Types to Form Expectations Intervals}

As we have shown, rounding varies substantially across respondents and the tendency to round is systematically associated with respondents’ observable characteristics. Yet, it is natural to wonder the extent to which failing to account for rounding might lead to inaccurate conclusions when analyzing data. A simple numerical illustration pertaining to the analysis of the effect of longevity expectations on hours worked shows that ignoring rounding may yield highly inaccurate conclusions.

Suppose that two respondents both round their response to the longevity expectation question to the closest multiple of 25 . Suppose that one respondent views their probability to live past age 75 to be forty percent while the other respondent views it to be sixty percent, with the latter working significantly more hours as a consequence. With rounding, both respondents report their probability to live past age 75 as fifty percent. The notable difference in hours-worked outcomes with apparently the same 
expectations may be misinterpreted as caused by unobserved heterogeneity in labor-leisure preferences, when the actual cause is different longevity expectations.

Table 7. Predicted Probabilities of Rounding Types for Selected Covariate Profiles

Panel A. Personal Health -(Female, White, Bachelor Degree) Respondents

\begin{tabular}{cccccc} 
Mean -1 & Mean & \multicolumn{2}{c}{ Average Cognition Across Waves } & \\
SD & Mean +1 & Mean -1 & Mean & Mean +1 \\
& & SD & SD & & SD
\end{tabular}

Prob. of Type (MC5-T, $\mathcal{M} 10-\mathrm{C})$

\begin{tabular}{|l|lll|}
\hline $50-59$ & 0.1846 & 0.2036 & 0.2198 \\
$60-69$ & 0.2136 & 0.2289 & 0.2402 \\
$70-79$ & 0.2008 & 0.2194 & 0.2347 \\
$80+$ & 0.1433 & 0.1658 & 0.1878 \\
\hline
\end{tabular}

Age

Across

Waves

\section{Prob. of Type (M100-T, M25-C)}

$\begin{array}{lll}0.0199 & 0.0157 & 0.0121\end{array}$

0.0135

0.0151

0.0247

0.0103

0.0119

0.0207

$80+$
0.0077

0.0091

0.0170
Prob. of Type (M 10-T, $\mathcal{M}$ 10-C)

\begin{tabular}{c|ccc|}
\hline $50-59$ & 0.3118 & 0.3123 & 0.3064 \\
$60-69$ & 0.2971 & 0.2897 & 0.2767 \\
$70-79$ & 0.2784 & 0.2768 & 0.2696 \\
$80+$ & 0.2494 & 0.2623 & 0.2701 \\
\hline
\end{tabular}

Prob. of Type (M $\mathcal{M} 100-\mathrm{T}, \mathcal{M} 50-\mathrm{C})$

50-59

60-69

70-79

$80+$

\begin{tabular}{|lll|}
\hline 0.0312 & 0.0221 & 0.0153 \\
0.0192 & 0.0133 & 0.0090 \\
0.0256 & 0.0180 & 0.0124 \\
0.0583 & 0.0433 & 0.0316 \\
\hline
\end{tabular}

Panel B. Personal Finances -(Female, White, Bachelor Degree) Respondents

\begin{tabular}{cccccc} 
& \multicolumn{4}{c}{ Average Cognition Across Waves } \\
Mean -1 & Mean & Mean +1 & Mean -1 & Mean & Mean +1 \\
SD & & SD & SD & & SD
\end{tabular}

Prob. of Type ( $\mathcal{M} 5$ 5-T, M10-C)

$50-59$
$60-69$
$70-79$
$80+$

Across

Waves

\begin{tabular}{|lll|}
\hline 0.2634 & 0.2724 & 0.2731 \\
0.2632 & 0.2722 & 0.2728 \\
0.2453 & 0.2621 & 0.2715 \\
0.1887 & 0.2162 & 0.2402 \\
\hline
\end{tabular}

Prob. of Type ( $\mathcal{M} 100-\mathrm{T}, \mathcal{M} 25-\mathrm{C})$

$50-59$
$60-69$
$70-79$
$80+$

\begin{tabular}{|lll|}
\hline 0.0072 & 0.0049 & 0.0032 \\
0.0071 & 0.0048 & 0.0031 \\
0.0102 & 0.0071 & 0.0048 \\
0.0196 & 0.0149 & 0.0109 \\
\hline
\end{tabular}

50-59
$60-69$
$70-79$
$80+$

50-59

60-69

70-79

$80+$
Prob. of Type ( $\mathcal{M} 10-\mathrm{T}, \mathcal{M} 10-\mathrm{C})$

\begin{tabular}{|lll|}
\hline 0.2483 & 0.2248 & 0.1976 \\
0.2440 & 0.2209 & 0.1942 \\
0.2583 & 0.2415 & 0.2191 \\
0.2665 & 0.2665 & 0.2586 \\
\hline
\end{tabular}

Prob. of Type ( $\mathcal{M} 100-\mathrm{T}, \mathcal{M} 50-\mathrm{C})$

\begin{tabular}{|lll|}
\hline 0.0107 & 0.0065 & 0.0038 \\
0.0107 & 0.0065 & 0.0038 \\
0.0175 & 0.0110 & 0.0067 \\
0.0443 & 0.0298 & 0.0194 \\
\hline
\end{tabular}




\begin{tabular}{|c|c|c|c|c|c|c|c|c|}
\hline & & $\begin{array}{c}\text { Mean -1 } \\
\text { SD }\end{array}$ & Mean & $\begin{array}{l}\text { Average } \\
\text { Mean }+1 \\
\text { SD }\end{array}$ & nition & $\begin{array}{c}\text { oss Waves } \\
\text { Mean }-1 \\
\text { SD }\end{array}$ & Mean & $\begin{array}{c}\text { Mean +1 } \\
\text { SD }\end{array}$ \\
\hline & & \multicolumn{3}{|c|}{ Prob. of Type ( $\mathcal{M} 5-\mathrm{T}, \mathcal{M} 10-\mathrm{C})$} & & \multicolumn{3}{|c|}{ Prob. of Type ( $\mathcal{M} 10-\mathrm{T}, \mathcal{M} 10-\mathrm{C})$} \\
\hline & $50-59$ & 0.2031 & 0.2170 & 0.2273 & $50-59$ & 0.3733 & 0.3724 & 0.3647 \\
\hline & $60-69$ & 0.2201 & 0.2315 & 0.2387 & $60-69$ & 0.3625 & 0.3562 & 0.3435 \\
\hline & $70-79$ & 0.2157 & 0.2298 & 0.2401 & $70-79$ & 0.3509 & 0.3495 & 0.3415 \\
\hline \multirow{6}{*}{$\begin{array}{c}\text { Average } \\
\text { Age } \\
\text { Across } \\
\text { Waves }\end{array}$} & $80+$ & 0.1671 & 0.1858 & 0.2027 & $80+$ & 0.3524 & 0.3658 & 0.3725 \\
\hline & & \multicolumn{3}{|c|}{ Prob. of Type ( $\mathcal{M} 100-\mathrm{T}, \mathcal{M} 25-\mathrm{C})$} & & \multicolumn{3}{|c|}{ Prob. of Type ( $\mathcal{M} 100-\mathrm{T}, \mathcal{M} 50-\mathrm{C})$} \\
\hline & $50-59$ & 0.0111 & 0.0088 & 0.0068 & $50-59$ & 0.0165 & 0.0116 & 0.0080 \\
\hline & $60-69$ & 0.0086 & 0.0067 & 0.0051 & $60-69$ & 0.0119 & 0.0082 & 0.0056 \\
\hline & $70-79$ & 0.0094 & 0.0074 & 0.0051 & $70-79$ & 0.0145 & 0.0101 & 0.0070 \\
\hline & $80+$ & 0.0166 & 0.0138 & 0.0112 & $80+$ & 0.0317 & 0.0233 & 0.0167 \\
\hline
\end{tabular}

NOTES: (i) ( $\mathcal{M}$ 5-T, $\mathcal{M} 10-\mathrm{C})$ denotes rounding to the nearest 5 percent or a finer degree in the tails and rounding to the nearest 10 percent or a finer degree in the center. $(\boldsymbol{M} 10-\mathrm{T}, \boldsymbol{\mathcal { M }} 10-\mathrm{C})$ denotes rounding to the nearest 10 percent or a finer degree in both the tails and the center. ( $\mathcal{M} 100-\mathrm{T}, \boldsymbol{\mathcal { M }} 25-\mathrm{C})$ denotes rounding to any degree in the tails and to the nearest 25 percent or a finer degree in the center. ( $\mathcal{M} 100-\mathrm{T}, \boldsymbol{\mathcal { M }} 50-\mathrm{C})$ denotes rounding to any degree in both the tails and the center. (ii) Predicted probabilities are evaluated at the mean value of average cognition across waves (denoted Mean), at the mean minus one standard deviation value of average cognition across waves (denoted Mean - 1 SD), and as the mean plus one standard deviation Value of average cognition across waves. Predicted probabilities are evaluated at average age across waves falling in each of the categories 50-59, 60-69, 70-79, and 80+.

Next, consider a scenario where the first respondent views their probability to live past age 75 to be thirty-seven percent while the other respondent views it to be thirty-eight percent, with the latter working slightly more hours. With rounding, the first respondent reports a probability to live past age 75 of twenty-five percent, and the second respondent reports fifty percent. The slight difference in outcomes with an apparent large difference in expectations may be misinterpreted as evidence of minimal effect of expectations on labor supply.

These examples, while stylized, illustrate that ignoring rounding might lead to "boundary mistakes;" that is, to significantly underestimating or overestimating an effect of interest. We therefore propose an algorithm that uses the information contained in each respondent's reporting behavior across the survey, as analyzed in the preceding sections, to transform observed percent-chance point reports into intervals.

Here we present the construction of interval data within the context of the illustration introduced in Section 3.1. The Supplementary Appendix 3.3 discusses more complex cases, presents the complete 
algorithm formally, and reports the distributions of interval width for the responses given to specific questions.

In the example introduced in Section 3.1, the respondent is observed to answer with $\{5,30,60,85\}$ to four expectations questions concerning personal finances and is classified to be of rounding type ( $\mathcal{M} 5$ - $\mathrm{T}, \mathcal{M} 10-\mathrm{C}$ ) in that domain. Because the respondent is classified to round to the nearest 5 percent in the tails, the algorithm assigns to each of the respondent's point responses in the tails an interval of width 5 centered around the point response. Specifically, the algorithm assigns the interval $[2.5,7.5]$ to response 5 (i.e., $5 \mp 2.5$ ) and the interval [82.5, 87.5] to response 85 (i.e., $85 \mp$ 2.5). Similarly, as the respondent is classified to round to the nearest 10 percent in the center, the algorithm assigns interval $[25,35]$ to the 30 percent response (i.e., $30 \mp 5$ ) and the interval $[55,65]$ to the 60 percent response (i.e., $60 \mp 5)$.

In general, construction of intervals around point responses near the thresholds which separate the center from the tails---that is, near 25 and 75 percent---requires specific "boundary conditions." Such conditions are not binding in this example. We explain them in the Appendix.

By construction, each interval contains the point response because the former is centered around the latter. Moreover, the interval is assumed to cover the unobserved true latent belief with certainty. However, no assumption is made about the location of the true latent belief inside the interval.

Our algorithm relies on considerably weaker and hence more credible assumptions than inference using expectations reports at face value. At the opposite extreme, one could be ultraconservative, maintaining that each point response is consistent with any amount of rounding. One would then replace all reported expectations with a $[0,100]$ interval. Obviously, doing this empties the data of any information content.

Our choice of assumptions used to identify respondents’ rounding types and bound their unobserved true beliefs strikes a balance between those two extremes and is informed by the respondents' response patterns across HRS questions and waves, which we have documented in this paper. A researcher 
entertaining a different set of assumptions about how survey respondents round their expectations reports could easily apply our framework by simply replacing our assumptions with theirs. In general, stronger and/or more numerous assumptions will yield (weakly) narrower intervals.

\section{Conclusion}

We have studied the nature of rounding in numerical reports of probabilistic expectations, a type of survey measure that has become widely used in empirical economic analysis of individual and household decisions under uncertainty. Our analysis of the responses to all expectations questions asked in the HRS core questionnaire between 2002 and 2014 confirms earlier findings based on analysis of the 2006 waves of data and establishes important new findings. We propose an inferential approach that interprets expectations reports as interval data and that explicitly incorporates the documented patterns of responses across waves, question domains, and location within the measurement scale.

The main tenet of the analysis is that observed response patterns across questions and waves carry information about individual respondents’ rounding practices. Observed response patterns, however, do not reveal whether individual respondents round their reports to simplify communication or to convey partial knowledge. Consistent with the first interpretation, we have assumed that respondents have wellformed latent point beliefs. If instead the relevant latent objects were sets or ranges of beliefs, the algorithm would still work as intended as long as the algorithm's interval completely includes the latent interval.

If respondents round to convey partial knowledge about the likelihood of future events of the kind HRS expectations questions refer to, it would be better to allow them to express their ambiguity directly. This could be achieved by allowing respondents to give either a single percent-chance value or a range as they see fit. Then range measures of subjective expectations may be analyzed using existing econometric tools for interval data. See Manski and Molinari (2010) and Giustinelli and Pavoni (2017) for exploratory data collection and analysis of this type. 


\section{References}

Amemiya, T. (1981). Qualitative Response Models: A Survey. Journal of Economic Literature 19(4), 1483-1536.

Armantier, O., W. Bruine de Bruin, S. Potter, G. Topa, W. van der Klaauw, and B. Zafar (2013). Measuring Inflation Expectations. Annual Review of Economics 5, 273-301.

Attanasio, O. (2009). Expectations and Perceptions in Developing Countries: Their Measurement and Their Use. American Economic Review 99(2), 87-92.

Beresteanu, A. and F. Molinari (2008). Asymptotic Properties for a Class of Partially Identified Models. Econometrica 76(4), 763-814.

Bruine de Bruin, W., P.S. Fischbeck, N.A. Stiber, and B. Fischhoff (2002). What Number is "FiftyFifty?”: Redistributing Excessive 50\% Responses in Elicited Probabilities. Risk Analysis 22(4), 713723.

Bureau of Labor Statistics, U.S. Department of Labor (2018), Occupational Employment Statistics, www.bls.gov/oes/ [accessed 1/28/2018].

Crimmins, E.M., J.K. Kim, K.M. Langa, and D.R. Weir (2011). Assessment of Cognition Using Surveys and Neuropsychological Assessment: The Health and Retirement Study and the Aging, Demographics, and Memory Study. The Journals of Gerontology, Series B: Psychological Sciences and Social Sciences 66B(S1), i162-i171.

Delavande, A. (2014). Probabilistic Expectations in Developing Countries. Annual Review of Economics $6,1-20$.

Dominitz, J. and C.F. Manski (1997). Using Expectations Data to Study Subjective Income Expectations. Journal of the American Statistical Association 92(439), 855-867.

Fischhoff, B. and W. Bruine de Bruin (1999). Fifty-Fifty $=50 \%$ ? Journal of Behavioral Decision Making 12, 149-163.

Fisher, G.G., H. Hassan, W.L. Rodgers, and D.R. Weir (2012). Health and Retirement Study Imputation of Cognitive Functioning Measures: 1992-2010 Early Release.

http://hrsonline.isr.umich.edu/modules/meta/xyear/cogimp/desc/COGIMPdd.pdf.

Gill, R.D., M.J. van der Laan, and J.M. Robins (1997). Coarsening at Random: Characterization, Conjectures, Counter-Examples. In Proceedings of the First Seattle Symposium in Biostatistics: Survival Analysis. Eds. D.Y. Lin and T.R. Fleming. Lecture Notes in Statistics. New York: Springer-Verlag, pp. 255-294.

Giustinelli, P. and C.F. Manski (2018). Survey Measures of Family Decision Processes for Econometric Analysis of Schooling Decisions. Economic Inquiry 56, 81-99.

Giustinelli, P. and N. Pavoni (2017). The Evolution of Awareness and Belief Ambiguity in the Process of High School Track Choice. Review of Economic Dynamics 25, 93-120. 
Heitjan, D.F. and D.B. Rubin (1991). Ignorability and Coarse Data. Annals of Statistics 19(4), 22442253.

Heitjan, D.F. (1994). Ignorability in General Incomplete-Data Models. Biometrika 81(4), 701-708.

Hudomiet, P. and R.J. Willis (2013). Estimating Second Order Probability Beliefs from Subjective Survival Data. Decision Analysis 10(2), 152-170.

Hurd, M.D. (2009). Subjective Probabilities in Household Surveys. Annual Review of Economics 1, 543562.

Juster, F.T. (1966). Consumer Buying Intentions and Purchase Probability: An Experiment in Survey Design. Journal of the American Statistical Association 61, 658-696.

Juster, F.T. and R. Suzman (1995). An overview of the Health and Retirement Study. Journal of Human Resources 30, S7-56.

Kleinjans, K.J. and A. van Soest (2014). Rounding, Focal Point Answers and Nonresponse to Subjective Probability Questions. Journal of Applied Econometrics 29, 567-585.

Lillard, L. and R.J. Willis (2001). Cognition and Wealth: The Importance of Probabilistic Thinking. Michigan Retirement Research Working Paper MRRC WP UM00-04, University of Michigan.

Manski, C.F. (1990). The Use of Intentions Data to Predict Behavior: A Best-Case Analysis. Journal of the American Statistical Association 85(412), 934-940.

Manski, C.F. (2004). Measuring Expectations. Econometrica 72, 1329-1376.

Manski, C.F. (2017). Survey Measurement of Probabilistic Macroeconomic Expectations: Progress and Promise. Manuscript prepared for the 2017 NBER Macro Annual Conference.

Manski, C.F. and F. Molinari (2010). Rounding Probabilistic Expectations in Surveys. Journal of Business and Economic Statistics 28(2), 219-231.

Manski, C.F. and E. Tamer (2002). Inference on Regressions with Interval Data on a Regressor or Outcome. Econometrica 70(2), 519-546.

Sajaia, Z. (2008). Maximum Likelihood Estimation of a Bivariate Ordered Probit Model: Implementation and Monte Carlo Simulations. Stata Journal 4, 1-18.

Schotter, A. and I. Trevino (2014). Belief Elicitation in the Laboratory. Annual Review of Economics 6, 103-128.

van der Klaauw, W. (2012). On the Use of Expectations Data in Estimating Structural Dynamic Models. Journal of Labor Economics 30(3), 521-554.

Wallsten, T.S. and B.H. Forsyth and D.V. Budescu (1983). Stability and Coherence of Health Experts' Upper and Lower Subjective Probabilities about Dose-Response Functions. Organizational Behavior and Human Performance 31, 277-302. 


\section{SUPPLEMENTARY MATERIAL}

\section{Supplementary Appendix to Section 2}

\section{SA2 Exploratory Analysis of Response Patterns Across Questions and Waves in the HRS}

Since 2002 the HRS has devoted an entire section of its core questionnaire to measurement of respondents' expectations in the domains of personal health, personal finances, and general economic conditions. Figure 1 in the main text shows the list of expectations questions asked in Section $\mathrm{P}$ of the HRS core questionnaire between 2002 and 2014 organized by domain.

As documented in Table S1, the number of responses varies across expectations questions. This occurs for several reasons. First, questions have been added and removed over time.

Second, the HRS makes extensive use of skip sequencing. In particular, whether a specific question is asked or not to a certain respondent may depend on the previous answers given by the respondent and on whether the event specified by the question is relevant to the respondent. For example, respondents who are older than 62 are not asked their subjective probability of working full-time past 62. Similarly, respondents who are older than 75 are not asked their subjective probability of living past 75, and so on. Moreover, respondents who respond 'Don't know' (DK) or 'Refuse' (RF) to three consecutive expectations questions are skipped to the next section.

Third, sample composition may change over time. In particular, the HRS sample has been augmented with new cohorts of respondents who joined the study in specific waves. On the other hand, respondents may exit the study due to attrition or death. 
Table S1: Number of Waves, Observations, and Respondents by Question

\begin{tabular}{lccc}
\hline Question: percent chance that... & $\begin{array}{c}\mathrm{N} \\
\text { waves } \\
\text { asked }\end{array}$ & $\begin{array}{c}\mathrm{N} \\
\text { total obs. } \\
\text { (across waves) }\end{array}$ & $\begin{array}{c}\text { N } \\
\text { Rs asked } \\
\text { (across waves) }\end{array}$ \\
\hline P19: Health limit work next 10 years & 1 & Personal Health & 5,475 \\
P28: Live to be age 75 or more & 7 & 5,475 & 17,868 \\
P29: Live to be age X or more & 7 & 56,497 & 27,638 \\
P32: Move to nursing home in 5 y & 7 & 118,404 & 26,095 \\
P103: Live independently at 75 & 2 & 74,696 & 5,693 \\
P104: Free of serious mental... at 75 & 2 & 7,590 & 5,693 \\
P106: Live independently at X & 2 & 7,590 & 13,228 \\
P107: Free of serious think/reason... & 4 & 15,291 & 15,599 \\
P108: Same health in 4 years & 2 & 33,518 & 12,509 \\
P109: Worse health in 4 years & 2 & 16,253 & 12,512 \\
\hline & & 16,232 & 19,598 \\
\hline P34: U.S. have economic depression & 4 & 50,661 & 27,279 \\
P47: Mutual funds up /next y & 7 & 105,714 & 24,868 \\
P110: SS in general will be worse & 5 & 71,770 & 16,680 \\
P114: Mutual fund up /more than living & 1 & 16,680 & 16,652 \\
P115: Mutual fund up 8\% /more than... & 1 & 16,652 & 17,781 \\
P116: Cost living up /more than 5\% & 2 & 32,431 & 20,051 \\
P150: Mutual funds up by 20/10/ X\% & 5 & 42,092 & 17,826 \\
P180: Mutual funds down by 20\% & 3 & 31,658 & 19,938 \\
P183: Medicare less generous in 10 y & 2 & 36,524 & 8,615 \\
P190: Stock market up by next year & 1 & 8,615 & 5,430 \\
P192: Stock market up by 20\% & 1 & 5,430 & 5,306 \\
P193: Stock market down by 20\% & 1 & 5,306 & Economic Conditions \\
\hline N015: Nof & & Gener & \\
\hline
\end{tabular}

NOTE: $\mathrm{N}$ of total observations includes all answers by any respondent in any wave to the corresponding question, including don't know/refuse. The set of questions each respondent is asked and observed to answer may vary across waves as a function of aspects of survey design such as the decision of designers to introduce new questions or to eliminate existing ones, the respondent's time-varying characteristics used for skip logic, etc. Additionally, new cohorts of respondents have been added over time, while a portion of respondents from the initial cohorts have left the study due to death or other reasons. 
Table S1 (Continued): Number of Waves, Observations, and Respondents by Question

\begin{tabular}{|c|c|c|c|}
\hline Question: percent chance that... & $\begin{array}{c}\mathrm{N} \\
\text { waves } \\
\text { asked } \\
\end{array}$ & $\begin{array}{c}\mathrm{N} \\
\text { total obs. } \\
\text { (across waves) }\end{array}$ & $\begin{array}{c}\mathrm{N} \\
\text { Rs asked } \\
\text { (across waves) }\end{array}$ \\
\hline \multicolumn{4}{|c|}{ Personal Finances } \\
\hline P4: Income keep up inflation in $5 \mathrm{y}$ & 3 & 51,559 & 20,852 \\
\hline P5: Leave inheritance $\geq \$ 10 \mathrm{~K}$ & 7 & 116,769 & 28,252 \\
\hline P6: Leave inheritance $\geq \$ 100 \mathrm{~K}$ & 7 & 95,625 & 25,360 \\
\hline P7: Leave any inheritance & 7 & 19,716 & 9,426 \\
\hline P8: Receive inheritance in $10 \mathrm{y}$ & 3 & 51,559 & 20,852 \\
\hline P14: Lose job next year & 6 & 32,743 & 12,220 \\
\hline P15: Find job in few months/loss & 6 & 32,727 & 12,220 \\
\hline P16: Work for pay in the future & 7 & 66,855 & 20,902 \\
\hline P17: Work full time after age 62 & 7 & 36,603 & 13,325 \\
\hline P18: Work full time after age 65 & 7 & 37,062 & 13,158 \\
\hline P20: Find job in few months/unemployed & 7 & 8,206 & 5,182 \\
\hline P30: Give $\$ 5 \mathrm{~K}$ to others in $10 \mathrm{y}$ & 3 & 50,528 & 20,633 \\
\hline P31: Receive $\$ 5 \mathrm{~K} \ldots$ in $10 \mathrm{y}$ & 3 & 50,528 & 20,633 \\
\hline P59: Leave inheritance $\geq \$ 500 \mathrm{~K}$ & 7 & 73,872 & 21,339 \\
\hline P70: Med expenses use up savings & 3 & 50,478 & 19,583 \\
\hline P71: Give $\$ 1 \mathrm{~K}$ to others in $10 \mathrm{y}$ & 2 & 21,024 & 13,717 \\
\hline P72: Give $\$ 10 \mathrm{~K}$ to others in $10 \mathrm{y}$ & 2 & 12,904 & 8,981 \\
\hline P73: Give $\$ 20 \mathrm{~K}$ to others in $10 \mathrm{y}$ & 2 & 11,155 & 7,838 \\
\hline P74: Receive $\$ 2.5 \mathrm{~K} \ldots$ in $10 \mathrm{y}$ & 2 & 30,644 & 18,014 \\
\hline P75: Receive $\$ 1 \mathrm{~K} \ldots$ in $10 \mathrm{y}$ & 2 & 30,397 & 17,924 \\
\hline P76: Receive $\$ 10 \mathrm{~K} \ldots$ in $10 \mathrm{y}$ & 2 & 3,270 & 2,786 \\
\hline P111: SS worse/current own benefits & 5 & 51,023 & 16,477 \\
\hline P112: SS worse/future own benefits & 5 & 26,753 & 10,599 \\
\hline P166: Home worth more next year & 3 & 28,067 & 11,422 \\
\hline P168: Home worth more/less by X & 3 & 26,394 & 11,168 \\
\hline P175: OP med exp $\geq \$ 1.5 \mathrm{~K}$ next year & 3 & 56,760 & 21,771 \\
\hline P176: OP med exp $\geq \$ 500$ next year & 3 & 10,962 & 7,482 \\
\hline P177: OP med exp $\geq \$ 3 K$ next year & 3 & 44,022 & 19,526 \\
\hline P178: OP med exp $\geq \$ 8 K$ next year & 3 & 36,369 & 17,453 \\
\hline P181: Any work after age 70 & 2 & 17,057 & 9,915 \\
\hline P182: Work full time after age 70 & 2 & 10,384 & 6,856 \\
\hline
\end{tabular}

NOTE: $\mathrm{N}$ of total observations includes all answers by any respondent in any wave to the corresponding question, including don't know/refuse. The set of questions each respondent is asked and observed to answer may vary across waves as a function of aspects of survey design such as the decision of designers to introduce new questions or to eliminate existing ones, the respondent's time-varying characteristics used for skip logic, etc. Additionally, new cohorts of respondents have been added over time, while a portion of respondents from the initial cohorts have left the study due to death or other reasons. 


\section{SA2.1 Temporal Stability of Response Tendencies}

We start by investigating the empirical distributions of responses to each of the questions listed in Table S1 above separately for each wave between 2002 and 2014. To reduce length, in Table S2 we present the response patterns for a subset of 9 questions in different domains. We focus on questions that were asked in at least 4 waves.

For each of the 9 questions selected and for each of the waves in which those questions were posed, the columns of Table S2 show the fractions of respondents who do not respond (NR), who respond 0 , 50, or 100, who respond with any other multiple of 10 percent (i.e., in $\mathbb{M} 10=\{10,20,30,40,60,70,80$, $90\}$ ), who respond with any multiple of 5 percent that is not a multiple of 10 percent (i.e., in $\mathbb{M} 5=\{5$, $15,25,35,45,55,65,75,85,95\})$, and who respond in two ranges of multiples of 1 percent that are not multiples of 5 or 10 percent (i.e., in 1-4 and in 96-99). In the column "Other" we report the residual fraction of respondents who respond with a multiple of 1 percent that does not lie in the 1-4 or 96-99 range.

By and large, HRS expectations questions feature low rates of item nonresponse in the personal health and personal finances domains (below 0.05) and higher rates of item nonresponse in the general economic conditions domain (typically between 0.05 and 0.10 ), with peaks of $0.25-0.30$ rates of nonresponse to specific questions eliciting respondents' expectations of future performance of the stock market (e.g., see question P47 in Table S2).

The rates of 0,50 , and 100 vary across questions. For example, the fraction of 50 percent responses tends to be higher in the general economic conditions domain, where they range between 0.20 and 0.30 , than in the remaining domains. Among the 9 questions shown in Table S2, the fractions of 0 and 100 are highest for specific questions belonging to the personal finances and personal health domains. For example, the fraction of 0 ranges between 0.35 and 0.50 for P14 (probability of losing own job during the next year) and for P32 (probability of moving to a nursing home in 5 years); whereas the fraction of 
100 percent is highest for P5 (probability of leaving an inheritance of at least \$10K), ranging between 0.324 and 0.447 across waves.

The high rates of 0,50 , and 100 in response to specific questions do not suggest any particular degree of rounding. For example, responses of 50 percent are consistent with any degree of rounding. Respondents who answered P47 (probability that the mutual fund will increase in value in the next year) might genuinely believe that it is equally likely that the stock market will increase or decrease in value in a 1-year time; they might mean that the chances that the stock market will go up are between 40 and 60 percent; or they might have epistemic uncertainty, using 50 percent to indicate a complete lack of knowledge.

Consistently high fractions of responses across questions and waves are multiples of 10 percent and, to a lesser extent, of 5 percent. For the 9 questions shown in Table S2, the fractions of M10 and M5 responses range respectively between 0.20 and 0.45 and between 0.05 and 0.15 across questions and waves. On the other hand, the fractions of cases where the response takes the value 1-4 or 96-99 are substantially smaller and range respectively between 0.002 and 0.035 and between 0.000 and 0.010 across questions and waves. Responses in the “Other” category occur even more infrequently and usually constitute 0.006 or less of cases.

The main takeaway from Table S2 is that the basic patterns found by Manski and Molinari (2010) using the 2006 data are confirmed for the remaining waves as well. Hence, these patterns are stable across waves. 
Table S2: Responses by Question and Wave in the 2002-2014 HRS

\begin{tabular}{|c|c|c|c|c|c|c|c|c|c|c|c|}
\hline \multirow[b]{2}{*}{ Question: percent chance that... } & \multirow[b]{2}{*}{ Wave } & \multirow[b]{2}{*}{$\mathrm{N}$} & \multicolumn{9}{|c|}{ Fraction of responses equal to or in: } \\
\hline & & & NR & 0 & $1-4$ & 50 & $96-99$ & 100 & M10 & M5 & Other \\
\hline \multirow{7}{*}{$\begin{array}{l}\text { P5: leave inheritance } \geq \$ 10,000 \\
\text { (personal finances) }\end{array}$} & 2002 & 16,119 & 0.050 & 0.154 & 0.004 & 0.074 & 0.007 & 0.443 & 0.205 & 0.060 & 0.002 \\
\hline & 2004 & 18,249 & 0.037 & 0.162 & 0.004 & 0.083 & 0.008 & 0.404 & 0.241 & 0.059 & 0.002 \\
\hline & 2006 & 17,191 & 0.053 & 0.159 & 0.004 & 0.067 & 0.008 & 0.447 & 0.209 & 0.052 & 0.001 \\
\hline & 2008 & 16,060 & 0.050 & 0.153 & 0.004 & 0.067 & 0.010 & 0.431 & 0.236 & 0.046 & 0.002 \\
\hline & 2010 & 20,397 & 0.037 & 0.172 & 0.007 & 0.080 & 0.009 & 0.344 & 0.296 & 0.053 & 0.003 \\
\hline & 2012 & 19,359 & 0.039 & 0.170 & 0.007 & 0.085 & 0.009 & 0.329 & 0.306 & 0.053 & 0.003 \\
\hline & 2014 & 17,647 & 0.037 & 0.167 & 0.006 & 0.086 & 0.008 & 0.324 & 0.319 & 0.050 & 0.003 \\
\hline \multirow{6}{*}{$\begin{array}{l}\text { P14: lose job during next year } \\
\text { (personal finances) }\end{array}$} & 2002 & 4,220 & 0.022 & 0.479 & 0.021 & 0.122 & 0.002 & 0.018 & 0.244 & 0.091 & 0.002 \\
\hline & 2004 & 5,629 & 0.013 & 0.450 & 0.021 & 0.128 & 0.000 & 0.019 & 0.277 & 0.091 & 0.001 \\
\hline & 2006 & 4,797 & 0.020 & 0.461 & 0.026 & 0.107 & 0.001 & 0.018 & 0.274 & 0.090 & 0.003 \\
\hline & 2010 & 6,785 & 0.018 & 0.323 & 0.028 & 0.141 & 0.001 & 0.022 & 0.356 & 0.106 & 0.004 \\
\hline & 2012 & 6,093 & 0.017 & 0.322 & 0.033 & 0.140 & 0.001 & 0.022 & 0.363 & 0.099 & 0.002 \\
\hline & 2014 & 5,219 & 0.015 & 0.323 & 0.035 & 0.126 & 0.001 & 0.018 & 0.376 & 0.103 & 0.003 \\
\hline \multirow{6}{*}{$\begin{array}{l}\text { P15: find equally good job } \\
\text { (personal finances) }\end{array}$} & 2002 & 4,220 & 0.022 & 0.183 & 0.009 & 0.165 & 0.006 & 0.142 & 0.353 & 0.120 & 0.001 \\
\hline & 2004 & 5,629 & 0.013 & 0.176 & 0.012 & 0.158 & 0.003 & 0.138 & 0.387 & 0.112 & 0.002 \\
\hline & 2006 & 4,797 & 0.017 & 0.173 & 0.014 & 0.152 & 0.004 & 0.143 & 0.383 & 0.112 & 0.003 \\
\hline & 2010 & 6,769 & 0.013 & 0.188 & 0.022 & 0.148 & 0.004 & 0.069 & 0.435 & 0.118 & 0.004 \\
\hline & 2012 & 6,093 & 0.014 & 0.166 & 0.018 & 0.164 & 0.003 & 0.076 & 0.447 & 0.108 & 0.003 \\
\hline & 2014 & 5,219 & 0.014 & 0.141 & 0.016 & 0.166 & 0.002 & 0.083 & 0.463 & 0.112 & 0.003 \\
\hline \multirow{7}{*}{$\begin{array}{l}\text { P17: work full time after age } 62 \\
\text { (personal finances) }\end{array}$} & 2002 & 3,219 & 0.012 & 0.194 & 0.005 & 0.139 & 0.005 & 0.220 & 0.312 & 0.111 & 0.001 \\
\hline & 2004 & 4,528 & 0.007 & 0.161 & 0.008 & 0.156 & 0.004 & 0.163 & 0.387 & 0.112 & 0.003 \\
\hline & 2006 & 5,238 & 0.011 & 0.299 & 0.011 & 0.133 & 0.004 & 0.142 & 0.305 & 0.093 & 0.002 \\
\hline & 2008 & 3,870 & 0.026 & 0.160 & 0.012 & 0.134 & 0.006 & 0.202 & 0.357 & 0.099 & 0.004 \\
\hline & 2010 & 7,828 & 0.008 & 0.152 & 0.014 & 0.151 & 0.006 & 0.143 & 0.415 & 0.108 & 0.004 \\
\hline & 2012 & 6,647 & 0.010 & 0.148 & 0.016 & 0.147 & 0.005 & 0.136 & 0.434 & 0.098 & 0.005 \\
\hline & 2014 & 5,294 & 0.006 & 0.147 & 0.015 & 0.142 & 0.005 & 0.137 & 0.443 & 0.099 & 0.005 \\
\hline
\end{tabular}

NOTE: $\mathrm{N}$ = sample size, $\mathrm{NR}$ = nonresponse, $\mathbb{M} 10$ = multiple of 10 but not $(0,50,100)$, M15 = multiple of 5 but not of 10. 
Table S2 (Continued): Responses by Question and Wave in the 2002-2014 HRS

\begin{tabular}{|c|c|c|c|c|c|c|c|c|c|c|c|}
\hline \multirow[b]{2}{*}{ Question: percent chance that... } & \multirow[b]{2}{*}{ Wave } & \multirow[b]{2}{*}{$\mathrm{N}$} & \multicolumn{9}{|c|}{ Fraction of responses equal to or in: } \\
\hline & & & NR & 0 & $1-4$ & 50 & 96-99 & 100 & M10 & M5 & Other \\
\hline \multirow{7}{*}{$\begin{array}{l}\text { P28: live to be } 75 \text { or more } \\
\text { (personal health) }\end{array}$} & 2002 & 7200 & 0.048 & 0.038 & 0.002 & 0.223 & 0.005 & 0.178 & 0.359 & 0.144 & 0.003 \\
\hline & 2004 & 9037 & 0.035 & 0.049 & 0.003 & 0.230 & 0.004 & 0.165 & 0.372 & 0.139 & 0.002 \\
\hline & 2006 & 6713 & 0.040 & 0.053 & 0.004 & 0.222 & 0.005 & 0.152 & 0.375 & 0.144 & 0.004 \\
\hline & 2008 & 5567 & 0.038 & 0.041 & 0.004 & 0.207 & 0.005 & 0.156 & 0.394 & 0.148 & 0.006 \\
\hline & 2010 & 10498 & 0.041 & 0.059 & 0.005 & 0.206 & 0.006 & 0.143 & 0.402 & 0.133 & 0.006 \\
\hline & 2012 & 9482 & 0.035 & 0.064 & 0.006 & 0.221 & 0.006 & 0.135 & 0.406 & 0.124 & 0.004 \\
\hline & 2014 & 8084 & 0.029 & 0.064 & 0.006 & 0.226 & 0.006 & 0.136 & 0.414 & 0.115 & 0.004 \\
\hline \multirow{7}{*}{$\begin{array}{l}\text { P32: move to nursing home in } 5 \text { years } \\
\text { (personal health) }\end{array}$} & 2002 & 9177 & 0.082 & 0.491 & 0.014 & 0.111 & 0.001 & 0.006 & 0.207 & 0.088 & 0.002 \\
\hline & 2004 & 12629 & 0.063 & 0.444 & 0.012 & 0.144 & 0.001 & 0.008 & 0.232 & 0.095 & 0.002 \\
\hline & 2006 & 10044 & 0.075 & 0.463 & 0.021 & 0.101 & 0.000 & 0.007 & 0.231 & 0.100 & 0.002 \\
\hline & 2008 & 10106 & 0.061 & 0.433 & 0.020 & 0.089 & 0.000 & 0.007 & 0.281 & 0.106 & 0.002 \\
\hline & 2010 & 15512 & 0.045 & 0.393 & 0.025 & 0.130 & 0.001 & 0.016 & 0.284 & 0.103 & 0.003 \\
\hline & 2012 & 9870 & 0.046 & 0.402 & 0.023 & 0.120 & 0.000 & 0.012 & 0.289 & 0.105 & 0.003 \\
\hline & 2014 & 9367 & 0.037 & 0.400 & 0.028 & 0.113 & 0.000 & 0.013 & 0.304 & 0.102 & 0.003 \\
\hline \multirow{4}{*}{$\begin{array}{l}\text { P34: U.S. have economic depression } \\
\text { (general economic conditions) }\end{array}$} & 2002 & 184 & 0.103 & 0.054 & 0.016 & 0.299 & 0.000 & 0.082 & 0.359 & 0.071 & 0.016 \\
\hline & 2004 & 17996 & 0.069 & 0.084 & 0.005 & 0.264 & 0.002 & 0.056 & 0.384 & 0.134 & 0.003 \\
\hline & 2006 & 16754 & 0.078 & 0.066 & 0.006 & 0.238 & 0.002 & 0.060 & 0.404 & 0.142 & 0.004 \\
\hline & 2008 & 15727 & 0.060 & 0.044 & 0.005 & 0.194 & 0.006 & 0.137 & 0.409 & 0.141 & 0.004 \\
\hline \multirow{4}{*}{$\begin{array}{l}\text { P110: Social Security will be less generous } \\
\text { (general economic conditions) }\end{array}$} & 2006 & 16754 & 0.065 & 0.048 & 0.003 & 0.231 & 0.005 & 0.120 & 0.387 & 0.139 & 0.002 \\
\hline & 2008 & 15727 & 0.064 & 0.049 & 0.002 & 0.223 & 0.006 & 0.111 & 0.395 & 0.147 & 0.003 \\
\hline & 2010 & 20208 & 0.046 & 0.048 & 0.005 & 0.191 & 0.010 & 0.187 & 0.379 & 0.130 & 0.005 \\
\hline & 2012 & 19081 & 0.043 & 0.051 & 0.004 & 0.210 & 0.008 & 0.175 & 0.387 & 0.118 & 0.004 \\
\hline \multirow{7}{*}{$\begin{array}{l}\text { P47: mutual fund increase in value } \\
\text { (general economic conditions) }\end{array}$} & 2002 & 7260 & 0.206 & 0.079 & 0.004 & 0.239 & 0.000 & 0.040 & 0.306 & 0.122 & 0.003 \\
\hline & 2004 & 17996 & 0.148 & 0.058 & 0.004 & 0.264 & 0.001 & 0.041 & 0.359 & 0.121 & 0.004 \\
\hline & 2006 & 16754 & 0.240 & 0.042 & 0.003 & 0.231 & 0.001 & 0.036 & 0.339 & 0.106 & 0.003 \\
\hline & 2008 & 15727 & 0.197 & 0.057 & 0.004 & 0.216 & 0.001 & 0.028 & 0.374 & 0.119 & 0.004 \\
\hline & 2010 & 20208 & 0.111 & 0.062 & 0.006 & 0.238 & 0.001 & 0.037 & 0.420 & 0.122 & 0.005 \\
\hline & 2012 & 19081 & 0.119 & 0.058 & 0.005 & 0.271 & 0.000 & 0.033 & 0.401 & 0.108 & 0.005 \\
\hline & 2014 & 8828 & 0.097 & 0.052 & 0.007 & 0.273 & 0.000 & 0.041 & 0.414 & 0.109 & 0.006 \\
\hline
\end{tabular}




\section{SA2.2 Pooling Data across Waves to Probe More Deeply into Response Tendencies}

The exploratory analysis presented in Section 2.1 of the main text describes the relative prevalence of rounding patterns aggregated across the HRS respondents. To obtain further insight, we examine in depth the rounding behavior of particular respondents across questions and waves. This kind of exploration is possible in the HRS, as each respondent has been asked and answered many expectations questions. Table S3 displays the average numbers of expectations questions asked and answered by HRS respondents, in total and by wave and question domain. This exploration yields important new findings, which we describe next.

We proceed by drawing a random subset of 100 HRS respondents and by generating histograms of the responses each respondent thus selected gave in each of the three question domains. Figure S1 illustrates using the respondent selected by the $9^{\text {th }}$ random draw.

Inspection of the histograms across the 100 randomly drawn respondents suggests that many of them may be applying weakly coarser rounding in the middle of the 0-100 percent chance scale than in its tails. To better visualize this pattern we report a grouped version of the histograms. For example, Figure S2 presents the grouped versions of the histograms shown in Figure S1 for respondent \#9. Specifically, in Figure S2 responses are grouped according to the following partition of the 0-100 scale, where 25 and 75 are used as the thresholds separating the center from the two symmetric tails: $\mathbb{M} 1$-Tail = values in 1$24 \cup 76-99$ that are not divisible by 5; $\mathbb{M} 1$-Center = values in $[26,74]$ that are not divisible by 5; M5Tail $=\{5,15,85,95\} ; \mathbb{M} 5-$ Center $=\{35,45,55,65\} ; \mathbb{M} 10-$ Tail $=\{10,20,80,90\} ; \mathbb{M} 10-$ Center $=\{30$, 40, 60, 70\}; M25 $=\{25,75\} ; \mathbb{M} 100=\{0,100\} ; \mathbb{M} 50=\{50\}$.

There are two notable features in the distributions of responses given by respondent \#9 in Figure S2. First, the high frequencies of 25 and 75 percent responses (grouped in M25) relative to other multiples of 5 (grouped in M5-T and M5-C) suggest that 25 and 75 may have special status among multiples of 5. 
These percentages correspond respectively to " 1 in 4 " and " 3 in 4" chances. Thus, they might be viewed by respondents as more rounded than other multiples of 5 .

The second important feature emerging from the histograms shown in Figure S2 is that the relative frequencies of refined responses in the tail segments of the scale are generally higher than the frequencies of such responses in the corresponding center segment. For instance, the heights of the bars corresponding to $\mathbb{M} 10-\mathrm{T}$ responses are systematically higher than those corresponding to $\mathbb{M} 10-\mathrm{C}$ responses in all three question domains. The same pattern applies to the remaining response categories. This suggests that the more frequent use of multiples of 1 percent near the endpoints of the scale than toward the middle of the scale documented by earlier analyses of rounding might be the expression of a more general tendency of respondents to round more coarsely around the middle of the 0-100 scale than in its tails. 
Table S3: Numbers of Questions Asked and Answered by Wave and Question Domain

\begin{tabular}{|c|c|c|c|c|c|c|c|c|}
\hline Wave & 2002 & 2004 & 2006 & 2008 & 2010 & 2012 & 2014 & All Waves \\
\hline \multicolumn{9}{|l|}{ Question Domain } \\
\hline personal finances & 14 & 21 & 23 & 11 & 18 & 20 & 20 & 127 \\
\hline personal health & 4 & 3 & 9 & 9 & 3 & 4 & 4 & 36 \\
\hline \multirow{3}{*}{$\begin{array}{l}\text { gen. economic cond. } \\
\text { total }\end{array}$} & 3 & 2 & 6 & 5 & 4 & 5 & 7 & 32 \\
\hline & 21 & 28 & 38 & 25 & 25 & 29 & 31 & 197 \\
\hline & \multicolumn{8}{|c|}{ Average Number of Questions Asked } \\
\hline personal finances & 8 & 12.4 & 13.2 & 5.6 & 9 & 9.7 & 9.7 & 67.6 \\
\hline personal health & 2.3 & 2.1 & 3.5 & 5.1 & 2.2 & 2.4 & 2.5 & 20.1 \\
\hline \multirow{3}{*}{$\begin{array}{r}\text { gen. economic cond. } \\
\text { total }\end{array}$} & 1 & 2 & 5.8 & 4.6 & 3.3 & 4.2 & 3.3 & 24.2 \\
\hline & 11.3 & 16.5 & 22.5 & 15.3 & 14.5 & 16.3 & 15.5 & 111.9 \\
\hline & \multicolumn{8}{|c|}{ Average Number of Questions Answered } \\
\hline personal finances & 7.8 & 12.1 & 12.8 & 5.4 & 8.9 & 9.5 & 9.5 & 66 \\
\hline personal health & 2.2 & 2 & 3.3 & 4.8 & 2.1 & 2.3 & 2.4 & 19.1 \\
\hline gen. economic cond. & 0.8 & 1.8 & 4.8 & 4.2 & 3 & 4 & 3.1 & 21.7 \\
\hline total & 10.8 & 15.9 & 20.9 & 14.4 & 14 & 15.8 & 15 & 106.8 \\
\hline
\end{tabular}


Figure S1: Distribution of Responses across Waves (2002-2014) of an Individual Respondent by Domain
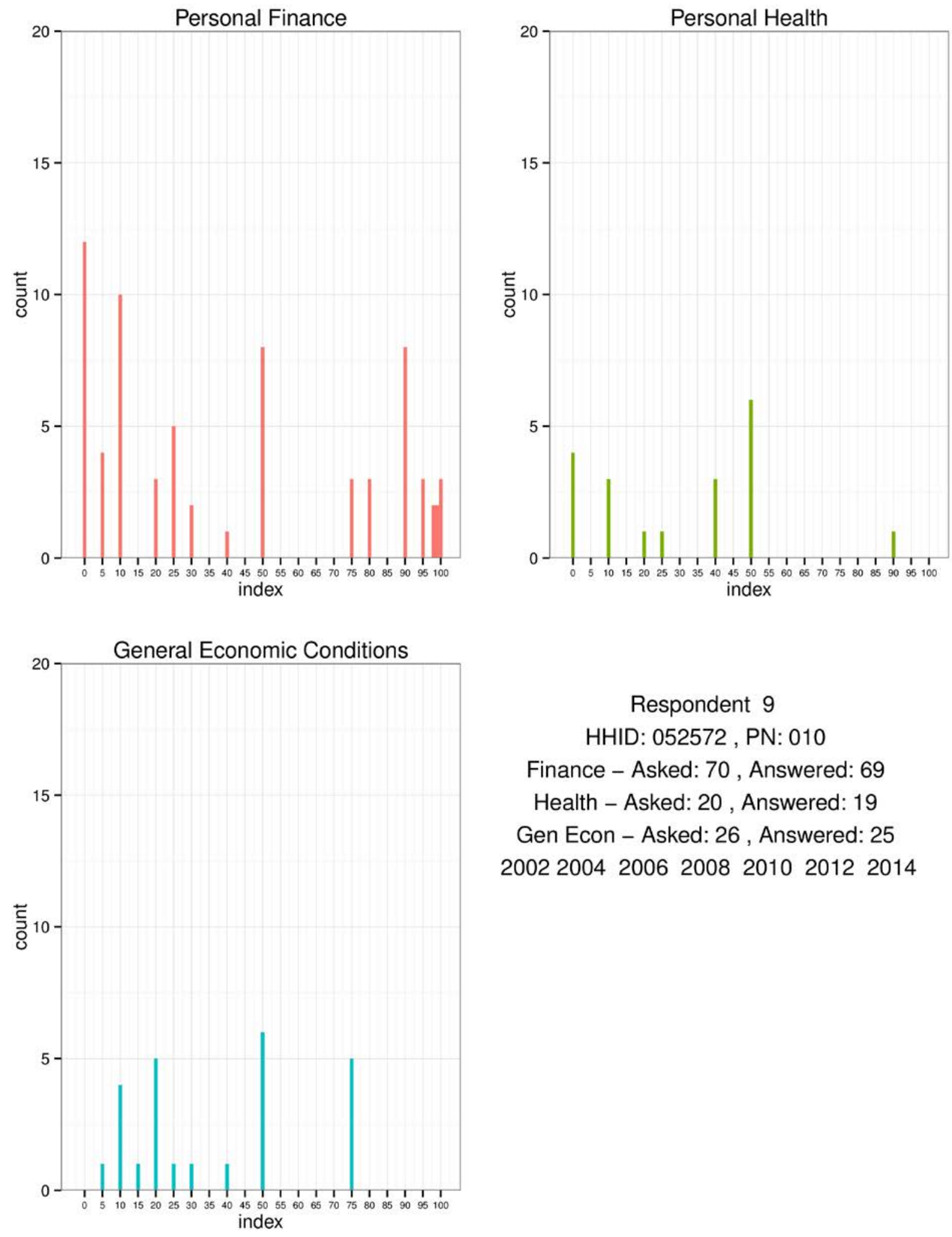

Respondent 9

HHID: 052572 , PN: 010

Finance - Asked: 70 , Answered: 69

Health - Asked: 20 , Answered: 19

Gen Econ - Asked: 26 , Answered: 25

2002200420062008201020122014 
Figure S2: Distribution of Responses across Waves (2002-2014) of an Individual Respondent by Domain: Grouped Version


Respondent 9

HHID: 052572 , PN: 010

Finance - Asked: 70 , Answered: 69

Health - Asked: 20 , Answered: 19

Gen Econ - Asked: 26 , Answered: 25

2002200420062008201020122014 


\section{Supplementary Appendix to Section 3}

\section{SA3.1 Determination of Respondent Rounding Types}

Table S4 presents in a formal and compact way the complete algorithm used to determine a respondent's rounding type in the center of the 0-100 scale (panel A) and in its tails (panel B) within a given question domain. Specifically, Table S4A maps all logically possible response tendencies that may be observed in the center of the 0-100 scale into corresponding center rounding types. Table S4B maps all logically possible response tendencies that may be observed in the tails of the $0-100$ scale into corresponding tail rounding types. For each question domain, each respondent is assigned a bivariate (tails, center) rounding type belonging to the cross product of the tail and center rounding types listed in the two panels of Table S4. Both panels make use of the partition of the 0-100 scale described in Table S5.

In Section 3.1, we present an example where a respondent is observed to answer four expectations questions in the domain of personal finances. The respondent's answers are $\{5,30,60,85\}$. As the set includes 2 multiples of 5 percent in the tails and 2 multiples of 10 percent in the center, the respondent is classified as rounding to the nearest 5 percent or finer degree in the tails ( $\mathcal{M} 5-\mathrm{T})$ and to the nearest 10 percent or finer degree in the center ( $\mathcal{M} 10-C)$.

We now discuss additional cases to further illustrate the logic of our proposed algorithm. Let us first consider an alternative scenario where the respondent is asked an additional question in the domain of personal finances and answers it with a value in the center that is either a multiple of 10 percent or 50 percent. Under this scenario, our conclusion about the respondent's rounding type in the center for the finances domain does not change. If, on the other hand, the respondent were to answer the additional question with a multiple of 5 percent in the center, our conclusion might change as it would depend on the respondent's response pattern in the two domains other than personal finances. For example, if in a second domain (say personal health), the respondent gave at least one center response that is a multiple 
of 5 percent or finer (i.e., a multiple of 1 percent), then the respondent would be classified as rounding to the nearest 5 percent (rather than 10 percent) in the center within the personal finances domain.

Moving now to the tails, let us imagine that the respondent is asked an additional question in the class of personal finances and answers it with a value in the tails that is a multiple of 5 percent, a multiple of 10 percent, or a focal response of 0 or 100 . In this case, our conclusion about the respondent's rounding type in the tails for the finances domain does not change. If, on the other hand, the respondent were to answer the additional question with a multiple of 1 percent in the tails, our conclusion might change depending on the respondent's response pattern in the other two domains. Specifically, if in a second domain (say general economic conditions), the respondent gave at least one response - either in the tails or in the center — that is a multiple of 1 percent, then the respondent would be classified as rounding to the nearest 1 percent in the tails within the personal finances domain.

Building on the example introduced in Section 3.1, in Section 3.3 we explain how to assign probability intervals to the respondents’ point responses. Here we discuss additional cases to further illustrate the logic of our algorithm, particularly the application of the boundary conditions in construction of the intervals.

Let us first consider a case where the respondent is asked an additional question (relative to the example discussed in Section 3.1) and were observed to answer with a multiple of 1 percent in the tails (say 2 percent). The respondent is still classified as $\mathcal{M} 5$-T in the tails, as long as they did not use any multiple of 1 percent to answer questions in the remaining domains. Under this scenario, construction of the interval around 2 percent requires a "boundary condition,” whereby the lower bound of the assigned interval cannot be smaller than 0 percent. Hence, if the respondent were observed to respond with 2 percent to one question in the finances domain, while still being classified as $\mathcal{M} 5$-T, 2 percent would be assigned the interval $[0,4.5]$ or $[\max (0,2-2.5), 2+2.5]$. In the right tail of the scale, a response of 98 
percent would be handled symmetrically and would be assigned a range of $[95.5,100]$ or $[98-2.5$, $\min (100,98+2.5)]$.

Let us now consider an alternative scenario where the respondent is asked two additional questions in the personal finances domain and is observed to answer both of them with a multiple of 1 percent in the tails (say 2 percent and 98 percent). We now classify the respondent as $\mathcal{M} 1-\mathrm{T}$. Under this scenario, all of the respondent's tail answers in the personal finances domain are taken at face value. Hence, 2 percent is assigned the range [2, 2], 5 percent is assigned the range [5, 5], and so on. Finally, regardless of the respondent's rounding type, any NR is assigned an interval of $[0,100]$.

Let us now entertain a final situation where the respondent's highest response in the left tail is 24 percent. In this case, the boundary condition to the left of 30 might bind, depending on the respondent's rounding type in the tails. Specifically, if the respondent is still $\mathcal{M} 5-\mathrm{T}-$ as it would happen if 24 percent were the only multiple of 1 percent (but not of 5 percent) used by the respondent in any domain — then the boundary condition to the left of 30 percent would bind, since $24+2.5>30-5$. In this case, the probability interval assigned to the response of 30 percent in the center would be [26.5, 35] instead of $[25,35]$. On the other hand, if the respondent were classified to be $\boldsymbol{M} 1-\mathrm{T}-$ as it would happen if they gave a second response, in addition to 24 percent, that is a multiple of 1 percent (but not of 5 percent) in any domain — then the boundary condition to the left of 30 percent would not bind, since 24 $<30-5$. 
Table S4A: Portion of the Algorithm Determining the Rounding Type of Respondent $j$ in the Center for Questions of Domain $I$

\begin{tabular}{|c|c|c|c|c|c|c|c|c|c|c|c|}
\hline $\begin{array}{ll}\text { START: } & \begin{array}{r}\text { AND } \exists \text { domain } \\
l \neq \neq l \\
\text { s.t. }\end{array} \\
\text { IF }\end{array}$ & $\begin{array}{l}\#\left(\Upsilon_{l^{\prime}} \cap\right. \\
\mathbb{M} 1-\mathrm{C}) \\
\geq 1\end{array}$ & $\begin{array}{l}\#\left(\Upsilon_{l^{\prime}} \cap\right. \\
\mathbb{M} 1-\mathrm{C}) \\
\quad=0\end{array}$ & $\begin{array}{l}\#\left(\Upsilon_{l^{\prime}} \cap\right. \\
\mathbb{M} 5-C) \\
\geq 1\end{array}$ & $\begin{array}{l}\#\left(\Upsilon_{l} \cap\right. \\
\mathbb{M} 5-C) \\
=0\end{array}$ & $\begin{array}{l}\#\left(\Upsilon_{l^{\prime}} \cap\right. \\
\mathbb{M} 10-\mathrm{C}) \\
\quad \geq 1\end{array}$ & $\begin{array}{l}\#\left(\Upsilon_{l} \cap\right. \\
\mathbb{M} 10-C) \\
\quad=0\end{array}$ & $\begin{array}{l}\#\left(\Upsilon_{l} \cap\right. \\
\mathbb{M} 25) \\
\geq 1\end{array}$ & $\begin{array}{l}\#\left(\Upsilon_{l^{\prime}} \cap\right. \\
\mathbb{M} 25) \\
=0\end{array}$ & $\begin{array}{l}\#\left(\Upsilon_{l} \cap\right. \\
\mathbb{M} 50) \\
\geq 1\end{array}$ & $\begin{array}{l}\#\left(\Upsilon_{l^{\prime}} \cap\right. \\
\mathbb{M} 50) \\
=0\end{array}$ & $\begin{array}{l}\text { All } \\
\text { NR }\end{array}$ \\
\hline$\#\left(\Upsilon_{l} \cap \mathbb{M} 1-C\right) \geq 2$ & \multicolumn{11}{|c|}{$j$ is $\mathcal{M} 1-\mathrm{C}$} \\
\hline$\#\left(\Upsilon_{l} \cap \mathbb{M} 1-C\right)=1$ & $\mathcal{M} 1-\mathrm{C}$ & \multicolumn{10}{|c|}{ IF $j$ is still UNCLASSIFIED, GO to the NEXT row } \\
\hline$\#\left(\Upsilon_{l} \cap\{\mathbb{M} 1-C \cup \mathbb{M} 5-C\}\right) \geq 2$ & \multicolumn{11}{|c|}{$j$ is $\mathcal{M} 5-\mathrm{C}$} \\
\hline$\#\left(\Upsilon_{l} \cap\{\mathbb{M} 1-C \cup \mathbb{M} 5-C\}\right)=1$ & $\mathcal{M} 5-\mathrm{C}$ & & $\mathcal{M} 5-\mathrm{C}$ & \multicolumn{8}{|c|}{ IF $j$ is still UNCLASSIFIED, GO to the NEXT row } \\
\hline $\begin{array}{l}\#\left(\Upsilon_{l} \cap\{\mathbb{M} 1-C \cup \mathbb{M} 5-C \cup\right. \\
\mathbb{M} 10-C\}) \geq 2\end{array}$ & \multicolumn{11}{|c|}{$j$ is $\mathcal{M} 10-\mathrm{C}$} \\
\hline $\begin{array}{l}\#\left(\Upsilon_{l} \cap\{\mathrm{M} 1-\mathrm{C} \cup \mathrm{M} 5-\mathrm{C} \cup\right. \\
\mathbb{M} 10-\mathrm{C}\})=1\end{array}$ & $\mathcal{M} 10-\mathrm{C}$ & & $\mathcal{M} 10-\mathrm{C}$ & & $\mathcal{M} 10-\mathrm{C}$ & \multicolumn{6}{|c|}{ IF $j$ is still UNCLASSIFIED, GO to the NEXT row } \\
\hline $\begin{array}{l}\#\left(\Upsilon_{l} \cap\{\mathbb{M} 1-C \cup \mathbb{M} 5-C \cup\right. \\
\mathbb{M} 10-C \cup \mathbb{M} 25\}) \geq 2\end{array}$ & \multicolumn{11}{|c|}{$j$ is $\mathcal{M} 25$} \\
\hline $\begin{array}{l}\#\left(\Upsilon_{l} \cap\{\mathbb{M} 1-C \cup \mathbb{M} 5-C \cup\right. \\
\mathbb{M} 10-C \cup \mathbb{M} 25\})=1\end{array}$ & $\mathcal{M} 25$ & & $\mathcal{M} 25$ & & $\mathcal{M} 25$ & & $\mathcal{M} 25$ & \multicolumn{4}{|c|}{$\begin{array}{l}\text { IF } j \text { is still UNCLASSIFIED, } \\
\text { GO to the NEXT row }\end{array}$} \\
\hline $\begin{array}{l}\#\left(\Upsilon_{l} \cap\{\mathbb{M} 1-C \cup \mathbb{M} 5-C \cup\right. \\
\mathbb{M} 10-C \cup \mathbb{M} 25 \cup \mathbb{M} 50\}) \geq 2\end{array}$ & \multicolumn{11}{|c|}{$j$ is $\mathcal{M} 50$} \\
\hline $\begin{array}{l}\#\left(\Upsilon_{l} \cap\{\mathbb{M} 1-C \cup \mathbb{M} 5-C \cup\right. \\
\mathbb{M} 10-C \cup \mathbb{M} 25 \cup \mathbb{M} 50\})=1\end{array}$ & $\mathcal{M C} 50$ & & $\mathcal{M C} 50$ & & $\mathcal{M} 50$ & & $\mathcal{M} 50$ & & $\mathcal{M} 50$ & \multicolumn{2}{|c|}{$\begin{array}{c}j \text { type is } \\
\boldsymbol{u} \text { ndetermined, } \\
\text { END }\end{array}$} \\
\hline All NR & \multicolumn{11}{|c|}{$j$ type is $\boldsymbol{U}$ ndetermined, END } \\
\hline
\end{tabular}

NOTE: $\Upsilon_{l}$ is the set of responses given by a hypothetical respondent $j$ in domain l. M1-C, M5-C, M10-C, M25, and M50 are sets partitioning the center of the 0-100 scale, defined in Table 6. $\mathcal{M} 1-\mathrm{C}, \boldsymbol{M} 5$-C, $\boldsymbol{M} 10-\mathrm{C}, \boldsymbol{\mathcal { M }} 25, \boldsymbol{M} 50$, and ' $\boldsymbol{U}$ ndetermined' denote rounding types in the center. $\mathcal{M} 1-\mathrm{C}$ denotes a respondent who rounds to the nearest 1 percent in the center, $\boldsymbol{\mathcal { M }} 5$-C denotes a respondent who rounds to the nearest 5 percent or finer in the center, and so on. $\boldsymbol{U}$ ndetermined denotes respondents who could not be classified to belong to any of the preceding center types. 
Table S4B: Portion of the Algorithm Determining the Rounding Type of Respondent $j$ in the Tails for Questions of Domain $l$

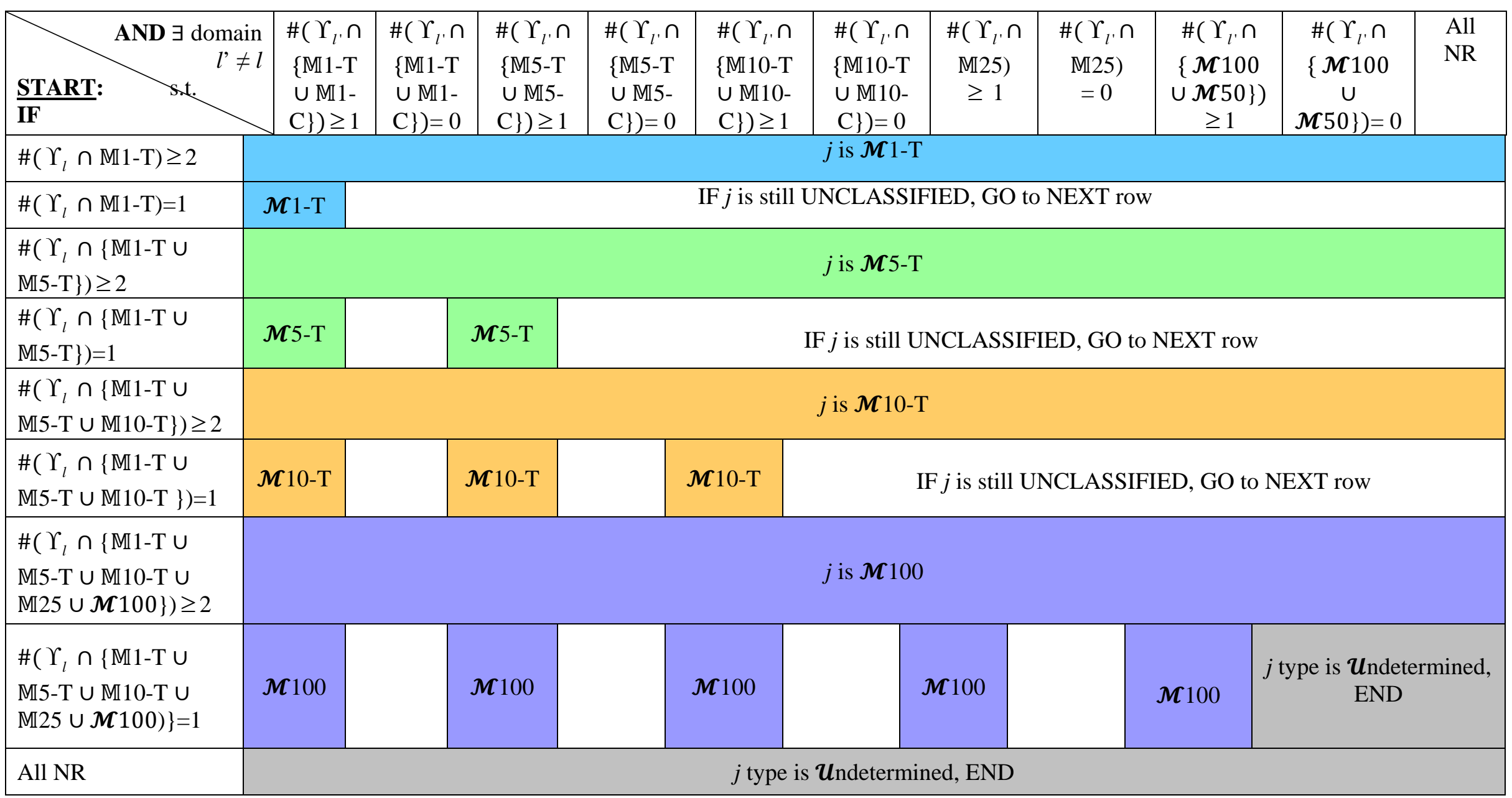

NOTE: $\Upsilon_{l}$ is the set of responses given by a hypothetical respondent $j$ in domain l. M1-T, M5-T, M10-T, and M100 are sets partitioning the tails of the 0100 scale, defined in Table 6. $\mathcal{M} 1-\mathrm{T}, \boldsymbol{\mathcal { M }} 5$-T, $\boldsymbol{\mathcal { M }} 10$-T, $\boldsymbol{\mathcal { M }} 100$, and ' $\boldsymbol{U}$ ndetermined' denote rounding types in the tails. $\mathcal{M} 1$ - $\mathrm{T}$ denotes a respondent who rounds to the nearest 1 percent in the tails, $\mathcal{M} 5$ - $\mathrm{T}$ denotes a respondent who rounds to the nearest 5 percent or finer in the tails, and so on. $\boldsymbol{U}$ ndetermined denotes respondents who could not be classified to belong to any of the preceding t types. 
Table S5: Partition of the 0-100 Percent Chance Scale in Two Symmetric Tails and a Center

\begin{tabular}{|c|c|c|c|c|c|}
\hline & $\begin{array}{c}\text { LT } \\
\text { (Left Tail) } \\
\end{array}$ & $\begin{array}{c}\mathrm{RT} \\
\text { (Right Tail) } \\
\end{array}$ & $\begin{array}{c}\mathrm{T} \\
\text { (Tail) }\end{array}$ & $\begin{array}{c}\mathrm{C} \\
\text { (Center) } \\
\end{array}$ & Union \\
\hline (M100,M50) & $\{0\}$ & $\{100\}$ & $\mathbb{M} 100-L T \cup \mathbb{M} 100-R T$ & $\{50\}$ & $\mathbb{M} 100 \cup \mathbb{M} 50$ \\
\hline M25 & $\varnothing$ & $\varnothing$ & $\varnothing$ & $\{25,75\}$ & M25 \\
\hline M10 & $\{10,20\}$ & $\{80,90\}$ & M10-LT U M10-RT & $\{30,40,60,70\}$ & M10-T U M10-C \\
\hline M5 & $\{5,15\}$ & $\{85,95\}$ & M5-LT U M5-RT & $\{35,45,55,65\}$ & M5-T U M5-C \\
\hline M1 & $\begin{array}{c}1-4 \cup 6-9 \cup 11-14 \\
\cup 16-19 \cup 21-24\end{array}$ & $\begin{array}{c}76-79 \cup 81-84 \cup 86-89 \\
\cup 91-94 \cup 96-99\end{array}$ & M1-LT U M1-RT & $\begin{array}{c}26-29 \cup 31-34 \cup 36-39 \cup 41-44 \\
\cup 46-49 \cup 51-54 \cup 56-59 \\
\cup 61-64 \cup 66-69 \cup 71-74 \\
\end{array}$ & $\mathbb{M} 1-\mathrm{T} \cup \mathbb{M} 1-\mathrm{C}$ \\
\hline Union & $\begin{array}{l}\text { M100-LT U M10-LT } \\
\cup \mathbb{M} 5-L T \cup \mathbb{M} 1-L T\end{array}$ & $\begin{array}{c}\text { M100-RT U M10-RT } \\
\text { U M5-RT U M1-RT }\end{array}$ & $\begin{array}{l}\text { M100 U M10-T } \\
\cup \text { M5-T U M1-T }\end{array}$ & $\begin{array}{c}\mathbb{M} 50 \cup \mathbb{M} 25 \cup \mathbb{M} 10-C \\
\cup \mathbb{M} 5-C \cup \mathbb{M} 1-C\end{array}$ & $\begin{array}{c}0-100 \\
\text { (entire scale) }\end{array}$ \\
\hline
\end{tabular}




\section{SA3.3 Variation of Rounding Types with Respondent Characteristics}

Before describing how probability intervals are formed based on respondents' point responses and their inferred rounding types, we investigate whether the latter vary systematically by respondents' characteristics. To this end, in Section 3.3 we estimate three bivariate ordered probit models, one per question domain, where the outcome variables are the respondent's bivariate vectors of tail and center rounding categories in the corresponding domains and the predictors are respondent's gender, age, educational attainment, race, and cognitive score.

Here we provide additional estimates from a specification that excludes cognitive scores. These estimates are shown in Table S6. We do so as we believe that this part of our analysis may yield useful information about likely characteristics of respondents that are associated with coarser or more refined rounding behavior to researchers who analyze survey expectations but do not have access to: (a) a sufficiently large number of expectations questions per respondent to directly apply our method; (b) a sufficiently rich or specialized set of relevant covariates as in the HRS.

The main patterns are analogous to those observed in the specification including cognitive scores. In particular, higher levels of educational attainment are still unambiguously and statistically significantly associated with a tendency to give more refined responses (less rounding) across all scale segments and question domains. Similarly, the dummies continue to display a non-linear effect. Respondents belonging to the oldest age category ( $80+$ ) have a statistically significant tendency to give more rounded responses than respondents belonging to the youngest one (50-59) across all scale segments and questions domains. On the other hand, respondents in the two intermediate age groups (i.e., 60-69 and 70-79) belong to rounding categories that may be more refined, coarser, or statistically indistinguishable from those characterizing younger respondents, depending on the specific domain or scale segment. Gender and race continue to features a somewhat mixed pattern. As before, rounding tendencies are 
positively correlated across scale segments. Hence, respondents who give coarser responses in the tails are more likely to do so in the center and vice versa.

Table S6: Bivariate Ordered Probit of (Tail, Center) Rounding Categories on Respondent’s Characteristics, by Question Domain

\begin{tabular}{|c|c|c|c|c|c|c|}
\hline & \multicolumn{2}{|c|}{ Personal Health } & \multicolumn{2}{|c|}{ Personal Finances } & \multicolumn{2}{|c|}{ Gen. Econ. Conditions } \\
\hline & Tail Type & Center Type & Tail Type & Center Type & Tail Type & Center Type \\
\hline \multirow[t]{2}{*}{ Male } & 0.0306 & -0.0203 & 0.0321 & 0.0166 & 0.0137 & -0.0346 \\
\hline & $(0.0146)$ & $(0.0152)$ & $(0.0139)$ & $(0.0149)$ & $(0.0147)$ & $(0.0154)$ \\
\hline \multirow[t]{2}{*}{ Aged 60-69 } & -0.1860 & -0.1343 & -0.0062 & 0.0217 & -0.1064 & -0.0962 \\
\hline & $(0.0177)$ & $(0.0191)$ & $(0.0171)$ & $(0.0186)$ & $(0.0182)$ & $(0.0192)$ \\
\hline \multirow[t]{2}{*}{ Aged 70-79 } & -0.1409 & 0.0784 & 0.1732 & 0.2271 & -0.7937 & 0.0562 \\
\hline & $(0.0196)$ & $(0.0203)$ & $(0.0187)$ & $(0.0201)$ & $(0.0196)$ & $(0.0205)$ \\
\hline \multirow[t]{2}{*}{ Aged 80+ } & 0.1768 & 0.5320 & 0.5862 & 0.6615 & 0.2228 & 0.4162 \\
\hline & $(0.0257)$ & $(0.0252)$ & $(0.0237)$ & $(0.0248)$ & $(0.0258)$ & $(0.0257)$ \\
\hline \multirow[t]{2}{*}{ High school } & -0.1749 & -0.1996 & -0.2507 & -0.2776 & -0.1250 & -0.2324 \\
\hline & $(0.0210)$ & $(0.0206)$ & $(0.0194)$ & $(0.0203)$ & $(0.0211)$ & $(0.0210)$ \\
\hline \multirow[t]{2}{*}{ Some college } & -0.1607 & -0.2081 & -0.2969 & -0.3290 & -0.1289 & -0.2820 \\
\hline & $(0.0346)$ & $(0.0359)$ & $(0.0326)$ & $(0.0351)$ & $(0.0347)$ & $(0.0367)$ \\
\hline \multirow[t]{2}{*}{ Bachelor } & -0.3400 & -0.4218 & -0.4566 & -0.4950 & -0.2714 & -0.4588 \\
\hline & $(0.0264)$ & $(0.0276)$ & $(0.0253)$ & $(0.0271)$ & $(0.0268)$ & $(0.0277)$ \\
\hline \multirow[t]{2}{*}{ Graduate } & -0.4362 & -0.5580 & -0.5459 & -0.5586 & -0.3513 & -0.5527 \\
\hline & $(0.0290)$ & $(0.0311)$ & $(0.0281)$ & $(0.0306)$ & $(0.0294)$ & $(0.0313)$ \\
\hline \multirow[t]{2}{*}{ Black } & 0.0846 & 0.1947 & -0.0548 & 0.0212 & -0.0036 & 0.0477 \\
\hline & $(0.0211)$ & $(0.0216)$ & (0.0193) & (0.0209) & $(0.0209)$ & $(0.0217)$ \\
\hline \multirow[t]{2}{*}{ Other race } & 0.1586 & 0.2031 & 0.1264 & 0.0897 & 0.1220 & 0.1128 \\
\hline & (0.0296) & $(0.0315)$ & $(0.0280)$ & $(0.0302)$ & $(0.0306)$ & $(0.0312)$ \\
\hline \multirow[t]{2}{*}{ Rho } & \multirow{2}{*}{\multicolumn{2}{|c|}{$\begin{array}{c}0.2698 \\
(0.0086)\end{array}$}} & \multirow{2}{*}{\multicolumn{2}{|c|}{$\begin{array}{c}0.3799 \\
(0.0073)\end{array}$}} & \multirow{2}{*}{\multicolumn{2}{|c|}{$\begin{array}{c}0.2985 \\
(0.0092)\end{array}$}} \\
\hline & & & & & & \\
\hline $\mathbf{N}$ & \multicolumn{2}{|c|}{22,821} & \multicolumn{2}{|c|}{25,016} & \multicolumn{2}{|c|}{22,983} \\
\hline
\end{tabular}

NOTES: (i) Respondents whose tail or center rounding category is undetermined are excluded from this analysis. (ii) Omitted dummies are 'Female,' 'Aged 50-59,' 'No degree,' and 'White.' 'Rho' is the parameter capturing the correlation between the error terms of the tail and center latent equations. (iii) Standard errors are reported in parentheses. 


\section{SA3.4 Using Survey Responses and Rounding Types to Form Expectations Intervals}

Table S7 (making use of the partition of the 0-100 scale described in Table S5) presents in a formal and compact way the complete portion of the algorithm used to assign intervals to observed point

responses in the scale tails (panel A) and in the its center (panel B) within a given domain. Specifically, Table S7A maps all logically possible rounding types and responses that may be observed in the tails of the 0-100 scale into corresponding tail intervals. Similarly, Table S7B maps all logically possible rounding types and responses that may be observed in the center of the 0-100 scale into corresponding center intervals. 
Table S7A: Portion of the Algorithm Assigning Probability Intervals, $\left[\boldsymbol{U}_{j k t L}^{T}, \boldsymbol{U}_{j k t U}^{T}\right]$, to Point Responses in the Tails by Respondent $j$ to Questions in Domain $l, U_{j k t}^{T}$, by Rounding Type

\begin{tabular}{|c|c|c|c|c|c|c|}
\hline $\begin{array}{l}\text { Center } \\
\text { Type } \\
\text { Tyils }\end{array}$ & $\mathcal{M} 1-\mathrm{C}$ & $\mathcal{M} 5-\mathrm{C}$ & $\mathcal{M} 10-\mathrm{C}$ & $\mathcal{M} 25$ & $\mathcal{M} 50$ & $\begin{array}{c}\text { No or } \boldsymbol{U} \text { ndetermined } \\
\text { center type }\end{array}$ \\
\hline $\mathcal{M} 1-\mathrm{T}$ & $v_{j k t}^{T}$ & $v_{j k t}^{T}$ & $v_{j k t}^{T}$ & $v_{j k t}^{T}$ & $v_{j k t}^{T}$ & $v_{j k t}^{T}$ \\
\hline $\mathcal{M} 5$ - Т & $\begin{array}{l}\text { SAME } \\
\text { AS } \\
(\mathcal{M} 1-\mathrm{T} \\
\mathcal{M} 1-\mathrm{C})\end{array}$ & $\begin{array}{l}{\left[\max \left(0, v_{j k t}^{T}-2.5\right),\right.} \\
\left.\min \left(v_{j k t}^{T}+2.5,100\right)\right]\end{array}$ & $\begin{array}{l}{\left[\max \left(0, v_{j k t}^{T}-2.5\right),\right.} \\
\left.\min \left(v_{j k t}^{T}+2.5,100\right)\right]\end{array}$ & $\begin{array}{l}{\left[\max \left(0, v_{j k t}^{T}-2.5\right)\right.} \\
\left.\min \left(v_{j k t}^{T}+2.5,100\right)\right]\end{array}$ & $\begin{array}{l}{\left[\max \left(0, v_{j k t}^{T}-2.5\right),\right.} \\
\left.\min \left(v_{j k t}^{T}+2.5,100\right)\right]\end{array}$ & $\begin{array}{l}{\left[\max \left(0, v_{j k t}^{T}-2.5\right),\right.} \\
\left.\min \left(v_{j k t}^{T}+2.5,100\right)\right]\end{array}$ \\
\hline $\mathcal{M} 10-\mathrm{T}$ & $\begin{array}{l}\text { SAME } \\
\text { AS } \\
(\mathcal{M} 1-\mathrm{T}, \\
\mathcal{M} 1-\mathrm{C}) \\
\end{array}$ & $\begin{array}{c}\text { SAME AS } \\
(\boldsymbol{M} 5-\mathrm{T}, \boldsymbol{M} 5 \text {-C) }\end{array}$ & $\begin{array}{l}{\left[\max \left(0, v_{j k t}^{T}-5\right),\right.} \\
\left.\min \left(v_{j k t}^{T}+5,100\right)\right]\end{array}$ & $\begin{array}{l}{\left[\max \left(0, v_{j k t}^{T}-5\right),\right.} \\
\left.\min \left(v_{j k t}^{T}+5,100\right)\right]\end{array}$ & $\begin{array}{l}{\left[\max \left(0, v_{j k t}^{T}-5\right),\right.} \\
\left.\min \left(v_{j k t}^{T}+5,100\right)\right]\end{array}$ & $\begin{array}{l}{\left[\max \left(0, v_{j k t}^{T}-5\right),\right.} \\
\left.\min \left(v_{j k t}^{T}+5,100\right)\right]\end{array}$ \\
\hline $\mathcal{M} 100$ & $\begin{array}{l}\text { SAME } \\
\text { AS } \\
(\mathcal{M} 1-\mathrm{T}, \\
\mathcal{M} 1-\mathrm{C})\end{array}$ & $\begin{array}{c}\text { SAME AS } \\
(\boldsymbol{M} 5-\mathrm{T}, \boldsymbol{M} 5 \text { - })\end{array}$ & $\begin{array}{c}\text { SAME AS } \\
(\boldsymbol{M} 10-\mathrm{T}, \boldsymbol{M} 10-\mathrm{C})\end{array}$ & $\begin{array}{l}{\left[\max \left(0, v_{j k t}^{T}-12.5\right)\right.} \\
\left.\min \left(v_{j k t}^{T}+12.5,100\right)\right]\end{array}$ & $\begin{array}{l}{\left[\max \left(0, v_{j k t}^{T}-25\right),\right.} \\
\left.\min \left(v_{j k t}^{T}+25,100\right)\right]\end{array}$ & $\begin{array}{l}{\left[\max \left(0, v_{j k t}^{T}-50\right),\right.} \\
\left.\min \left(v_{j k t}^{T}+50,100\right)\right]\end{array}$ \\
\hline $\begin{array}{l}\text { No or } \\
\boldsymbol{u} \text { ndet. } \\
\text { tail type }\end{array}$ & $\begin{array}{l}\text { SAME } \\
\text { AS } \\
(\mathcal{M} 1-\mathrm{T}, \\
\mathcal{M} 1-\mathrm{C})\end{array}$ & $\begin{array}{c}\text { SAME AS } \\
(\boldsymbol{M} 5-\mathrm{T}, \boldsymbol{M} 5-\mathrm{C})\end{array}$ & $\begin{array}{c}\text { SAME AS } \\
(\boldsymbol{M} 10-\mathrm{T}, \boldsymbol{\mathcal { M }} 10-\mathrm{C})\end{array}$ & $\begin{array}{c}\text { SAME AS } \\
(\boldsymbol{M} 100, \boldsymbol{M} 25)\end{array}$ & $\begin{array}{c}\text { SAME AS } \\
(\boldsymbol{M} 100, \boldsymbol{M} 50)\end{array}$ & {$[0,100]$} \\
\hline $\begin{array}{l}\text { All NR } \\
\text { responses } \\
\text { regardless } \\
\text { of type }\end{array}$ & {$[0,100]$} & {$[0,100]$} & {$[0,100]$} & {$[0,100]$} & {$[0,100]$} & {$[0,100]$} \\
\hline
\end{tabular}

NOTE: $\mathcal{M} 1-\mathrm{T}, \boldsymbol{M} 5$-T, $\boldsymbol{M} 10-\mathrm{T}, \boldsymbol{M} 100$, and ' $\boldsymbol{U}$ ndetermined' denote rounding types in the tails. $\boldsymbol{U}_{j k t}^{T}$ denotes a hypothetical response respondent $j$ gave in the tails of the 0-100 scale when answering a question in domain $l .\left[U_{j k t}^{T}, \bigcup_{j k t U}^{T}\right]$ denotes the probability interval assigned to the point response by the algorithm. The boundary conditions ensure that the lower and upper bounds of the probability interval lie in the tails of the 0-100 scale. 
Table S7B: Portion of the Algorithm Assigning Probability Intervals, $\left[U_{j k t L}^{C}, U_{j k t U}^{C}\right]$, to Point Responses in the Center by Respondent $j$ to Questions in Domain $l, U_{j k t}^{C}$, by Rounding Type

\begin{tabular}{|c|c|c|c|c|c|c|}
\hline $\begin{array}{l}\text { Center } \\
\text { Type } \\
\text { Tails } \\
\text { Type }\end{array}$ & $\mathcal{M} 1-\mathrm{C}$ & $\mathcal{M} 5-\mathrm{C}$ & $\mathcal{M} 10-\mathrm{C}$ & $\mathcal{M} 25$ & $\mathcal{M} 50$ & $\begin{array}{c}\text { No or } \\
\boldsymbol{U} \text { ndet. } \\
\text { center } \\
\text { type or } \\
\text { any NR } \\
\end{array}$ \\
\hline $\mathcal{M} 1-\mathrm{T}$ & $v_{j k t}^{C}$ & $\begin{array}{l}{\left[\max \left(\max \Upsilon_{j}^{L T}, v_{j k t}^{C}-2.5\right),\right.} \\
\left.\min \left(v_{j k t}^{C}+2.5, \min \Upsilon_{j}^{R T}\right)\right]\end{array}$ & $\begin{array}{l}{\left[\max \left(\max \Upsilon_{j}^{L T}, v_{j k t}^{C}-5\right),\right.} \\
\left.\min \left(v_{j k t}^{C}+5, \min \Upsilon_{j}^{R T}\right)\right]\end{array}$ & $\begin{array}{l}{\left[\max \left(\max \Upsilon_{j}^{L T}, v_{j k t}^{C}-12.5\right)\right.} \\
\left.\min \left(v_{j k t}^{C}+12.5, \min \Upsilon_{j}^{R T}\right)\right]\end{array}$ & $\begin{array}{l}{\left[\max \left(\max \Upsilon_{j}^{L T}, v_{j k t}^{C}-25\right),\right.} \\
\left.\min \left(v_{j k t}^{C}+25, \min \Upsilon_{j}^{R T}\right)\right]\end{array}$ & {$[0,100]$} \\
\hline $\mathcal{M} 5$ - $\mathrm{T}$ & $\begin{array}{c}\text { AS } \\
(\mathcal{M} 1 \mathrm{~T}, \\
\mathcal{M} 1 \mathrm{C}) \\
\end{array}$ & $\begin{array}{l}{\left[\max \left(\max \Upsilon_{j}^{L T}+2.5, v_{j k t}^{C}-2.5\right)\right.} \\
\left.\min \left(v_{j k t}^{C}+2.5, \min \Upsilon_{j}^{R T}-2.5\right)\right]\end{array}$ & $\begin{array}{l}{\left[\max \left(\max \Upsilon_{j}^{L T}+2.5, v_{j k t}^{C}-5\right),\right.} \\
\left.\min \left(v_{j k t}^{C}+5, \min \Upsilon_{j}^{R T}-2.5\right)\right]\end{array}$ & $\begin{array}{l}{\left[\max \left(\max \Upsilon_{j}^{L T}+2.5, v_{j k t}^{C}-12.5\right)\right.} \\
\left.\min \left(v_{j k t}^{C}+12.5, \min \Upsilon_{j}^{R T}-2.5\right)\right]\end{array}$ & $\begin{array}{l}{\left[\max \left(\max \Upsilon_{j}^{L T}+2.5, v_{j k t}^{C}-25\right)\right.} \\
\left.\min \left(v_{j k t}^{C}+25, \min \Upsilon_{j}^{R T}-2.5\right)\right]\end{array}$ & {$[0,100]$} \\
\hline $\mathcal{M} 10-\mathrm{T}$ & $\begin{array}{l}\text { AS } \\
(\mathcal{M} 1 \mathrm{~T}, \\
\mathcal{M} 1 \mathrm{C})\end{array}$ & $\begin{array}{c}\text { SAME AS } \\
(\boldsymbol{M} 5-\mathrm{T}, \boldsymbol{M} 5 \text {-C) }\end{array}$ & $\begin{array}{l}{\left[\max \left(\max \Upsilon_{j}^{L T}+5, v_{j k t}^{C}-5\right)\right.} \\
\left.\min \left(v_{j k t}^{C}+5, \min \Upsilon_{j}^{R T}-5\right)\right]\end{array}$ & $\begin{array}{l}{\left[\max \left(\max \Upsilon_{j}^{L T}+5, v_{j k t}^{C}-12.5\right)\right.} \\
\left.\min \left(v_{j k t}^{C}+12.5, \min \Upsilon_{j}^{R T}-5\right)\right]\end{array}$ & $\begin{array}{l}{\left[\max \left(\max \Upsilon_{j}^{L T}+5, v_{j k t}^{C}-25\right)\right.} \\
\left.\min \left(v_{j k t}^{C}+25, \min \Upsilon_{j}^{R T}-5\right)\right]\end{array}$ & {$[0,100]$} \\
\hline $\mathcal{M} 100$ & $\begin{array}{c}\text { AS } \\
(\mathcal{M} 1 \mathrm{~T}, \\
\mathcal{M} 1 \mathrm{C}) \\
\end{array}$ & $\begin{array}{c}\text { SAME AS } \\
(\boldsymbol{M} 5-\mathrm{T}, \boldsymbol{M} 5 \text { - }) ~\end{array}$ & $\begin{array}{c}\text { SAME AS } \\
(\boldsymbol{M} 10-\mathrm{T}, \boldsymbol{M} 10-\mathrm{C})\end{array}$ & {$\left[v_{j k t}^{C}-12.5, v_{j k t}^{C}+12.5\right]$} & $\begin{array}{l}{\left[\max \left(25, v_{j k t}^{C}-25\right)\right.} \\
\left.\min \left(v_{j k t}^{C}+25,75\right)\right]\end{array}$ & {$[0,100]$} \\
\hline $\begin{array}{l}\text { No or } \\
\boldsymbol{U} \text { ndet. } \\
\text { tail type }\end{array}$ & $\begin{array}{c}\text { AS } \\
(\mathcal{M} 1 \mathrm{~T} \\
\mathcal{M} 1 \mathrm{C})\end{array}$ & $\begin{array}{c}\text { SAME AS } \\
(\boldsymbol{M} 5-\mathrm{T}, \boldsymbol{M} 5 \text {-C })\end{array}$ & $\begin{array}{c}\text { SAME AS } \\
(\boldsymbol{M} 10-\mathrm{T}, \boldsymbol{M} 10-\mathrm{C})\end{array}$ & $\begin{array}{c}\text { SAME AS } \\
(\boldsymbol{M} 100, \boldsymbol{M} 25)\end{array}$ & $\begin{array}{l}\text { SAME AS } \\
(\boldsymbol{M} 100, \boldsymbol{M} 50)\end{array}$ & {$[0,100]$} \\
\hline
\end{tabular}

NOTE: $\mathcal{M} 1$-C, $\mathcal{M}$ 5-C, $\mathcal{M}$ 10-C, $\mathcal{M}$ 50, and ' $\boldsymbol{U}$ ndetermined' denote rounding types in the tails. $\boldsymbol{U}_{j k t}^{C}$ denotes a hypothetical response respondent $j$ gave in the center of the 0-100 scale when answering a question in domain $l .\left[\boldsymbol{U}_{j k t L}^{C}, \boldsymbol{U}_{j k t U}^{C}\right]$ denotes the probability interval assigned to the point response by the algorithm. The boundary conditions ensure that the lower and upper bounds of the probability interval lie in the center of the 0-100 scale. $\Upsilon_{j}^{L T}$ denotes the set of responses respondent $j$ gave in the left tail (i.e., in 0-24) when answering questions in domain $l . \Upsilon_{j}^{R T}$ denotes the set of respondent $j$ 's responses in the right tail (i.e., in 76-100). 
We apply the algorithm described in Table S7 to all responses by HRS respondents who responded to at least one expectations question in any question domain and in any wave between 2002 and 2014. For the purpose of constructing the intervals, respondents who were classified as rounding more coarsely in the tails than in the center are now treated as respondents who were classified as rounding to the same degree in the tails and in the center.

Table S8 reports the distributions of interval width for the responses given in wave 2014 to the following three questions: the percent chance that the respondent will live to be 75 or older (P28), the percent chance that the respondent will work full time past age 62 (P17), and the percent chance that a mutual fund will increase in value within the next year (P47).

The distribution of interval width for the probability of working past 62 displayed in the middle column of the table displays higher frequencies at lower width values than the distributions shown in the remaining columns, consistent with the pattern shown in Table 5 of the main text. 
Table S8: Distribution of Range Size for Specific Expectations Questions in the 2014 HRS

\begin{tabular}{|c|c|c|c|}
\hline Range Size & $\begin{array}{c}\text { Percent } \\
\text { Live to be } 75 \\
\text { or older } \\
\text { (P28 in Personal Health) }\end{array}$ & $\begin{array}{c}\text { Percent } \\
\text { Work full time } \\
\text { past age } 62 \\
\text { (P17 in Personal } \\
\text { Finances) }\end{array}$ & $\begin{array}{c}\text { Percent } \\
\text { Mutual funds } \\
\text { increase in value } \\
\text { (P47 in General } \\
\text { Economic Conditions) }\end{array}$ \\
\hline 0 & 7.17 & 20.95 & 6.04 \\
\hline 2.5 & 3.71 & 9.05 & 2.02 \\
\hline 3.5 & 0.09 & 0.09 & 0 \\
\hline 4.5 & 0.04 & 0.08 & 0.02 \\
\hline 5 & 27.72 & 31.72 & 23.82 \\
\hline 6 & 0.01 & 0.02 & 0 \\
\hline 7.5 & 0.99 & 1.38 & 1.55 \\
\hline 9 & 0.02 & 0.02 & 0 \\
\hline 10 & 42.96 & 32.58 & 48.11 \\
\hline 12.5 & 1.53 & 0.34 & 0.77 \\
\hline 15 & 0.38 & 0.19 & 0.36 \\
\hline 17.5 & 0.06 & 0.13 & 0.11 \\
\hline 20 & 0.05 & 0.02 & 0.02 \\
\hline 22.5 & 0.06 & 0.11 & 0.09 \\
\hline 25 & 4.40 & 1.57 & 3.77 \\
\hline 27.5 & 0.02 & 0 & 0 \\
\hline 30 & 0.02 & 0.02 & 0.01 \\
\hline 32.5 & 0 & 0.02 & 0 \\
\hline 35 & 0.01 & 0 & 0 \\
\hline 40 & 0 & 0 & 0.02 \\
\hline 42.5 & 0.01 & 0 & 0 \\
\hline 50 & 7.71 & 1.1 & 3.56 \\
\hline 60 & 0.01 & 0 & 0 \\
\hline 100 & 2.99 & 0.62 & 9.72 \\
\hline Total & 100 & 100 & 100 \\
\hline Sample size & 8,084 & 5,294 & 8,828 \\
\hline
\end{tabular}

